Illinois State University

ISU ReD: Research and eData

Theses and Dissertations

4-14-2021

\title{
In Defense Of Plants: Salicylic Acid In A Host-Parasite-Pathogen System
}

Timothy Kyle Martin

Illinois State University, mart9242@gmail.com

Follow this and additional works at: https://ir.library.illinoisstate.edu/etd

Part of the Ecology and Evolutionary Biology Commons

\section{Recommended Citation}

Martin, Timothy Kyle, "In Defense Of Plants: Salicylic Acid In A Host-Parasite-Pathogen System" (2021). Theses and Dissertations. 1388.

https://ir.library.illinoisstate.edu/etd/1388

This Thesis is brought to you for free and open access by ISU ReD: Research and eData. It has been accepted for inclusion in Theses and Dissertations by an authorized administrator of ISU ReD: Research and eData. For more information, please contact ISUReD@ilstu.edu. 


\section{IN DEFENSE OF PLANTS: SALICYLIC ACID IN A HOST-PARASITE-PATHOGEN}

\section{SYSTEM}

\section{TIMOTHY MARTIN}

48 Pages

Cuscuta pentagona is an obligate parasitic plant that uses a specialized organ, known as a haustorium, to penetrate host xylem and phloem to absorb water and nutrients from its hosts. As holoparasites, they lack chloroplast and therefore cannot photosynthesize. Bidirectional movement at the haustoria raises the possibility that the parasite can transmit defense signals from one host to another, though in what form is unclear. The biotrophic feeding mode, lack of chloroplast, and bidirectional movement across the haustoria lead me to hypothesize that (1) $C$. pentagona as a shoot parasite would elicit a systemic acquired resistance response in a host that would be observable in Cuscuta, (2) C. pentagona would be unable to synthesize salicylic acid without a host because it lacks chloroplast, and (3) that Cuscuta transmit salicylic acid molecules that are not utilized in the parasite between hosts because excess salicylic acid would not be beneficial to Cuscuta. I predicted that (1) salicylic acid would be higher in tomatoes infected with $C$. pentagona and a salicylic response to subsequent attack by the root pathogen Phytophthora nicotianae would be elevated, (2) C. pentagona would be deficient in salicylic acid without a host and would have increased salicylic acid content when challenged while attached to a host, and (3) C. pentagona would move the salicylic acid from a primary host to a secondary host and prime the secondary plant's salicylic acid defense response. Cuscuta pentagona was attached to tomato (Solanum lycopersicum) plants and challenges - in the form of infection by a second parasite Phytophthora nicotianae (Experiments $1 \& 3$ ), needle puncture, 
and exposure to Methyl salicylic acid (Experiment 2) - were introduced to elicit a defense response in either the tomatoes or Cuscuta. Treatment by $P$. nicotianae decreased salicylic acid in tomato roots but Cuscuta did not elicit a response or alter the effect of P. nicotianae. Nonetheless, an increased amount of salicylic was observed in the Cuscuta when attached to a host infected by P. nicotianae. Significant levels of salicylic acid in unattached Cuscuta seedlings showed that they are able to independently produce salicylic acid, rejecting hypothesis (2). Treatment of the Cuscuta with needle and methyl salicylic acid did not produce significant changes in salicylic acid concentration. I found no evidence of direct transfer of salicylic acid by Cuscuta bridging, but there was diminished salicylic acid in the roots of secondary plants in pairs infected with $P$. nicotianae, rejecting hypothesis (3). There appears to be interaction between Cuscuta and its hosts via salicylic acid, but further experimentation is needed to fully elucidate the mechanisms of this interaction.

KEYWORDS: Salicylic Acid, Signal, Cuscuta pentagona, Solanum lycopersicum, Phytophthora Nicotianae, Coinfection 


\title{
IN DEFENSE OF PLANTS: SALICYLIC ACID IN A HOST-PARASITE-PATHOGEN SYSTEM
}

TIMOTHY MARTIN

\author{
A Thesis Submitted in Partial \\ Fulfillment of the Requirements \\ for the Degree of \\ MASTER OF SCIENCE \\ School of Biological Sciences \\ ILLINOIS STATE UNIVERSITY
}

2021 
Copyright 2021 Timothy K. Martin 
IN DEFENSE OF PLANTS: SALICYLIC ACID IN A HOST-PARASITE-PATHOGEN SYSTEM

\section{TIMOTHY MARTIN}

COMMITTEE MEMBERS:

Victoria A. Borowicz, Chair

John C. Sedbrook

Ben M. Sadd 


\section{ACKNOWLEDGMENTS}

A special thanks to Dr. Borowicz for her patience, support, and guidance throughout my time spent on this project and as a student. I would also thank my committee members, Dr. Sedbrook and Dr. Sadd for their support and time. Additional thanks to my fellow graduate students J. Fowler, A. Scheidel, as well as undergraduates E. Berry, H. Smith, A. Borries, K. Cazzato, J. Howard, A. Morgan, J. Edmondson, and A. Gardner for their assistance with greenhouse and lab experimentation. Thank you to my friends and family for their support during my time as a graduate student. This research was funded by Phi Sigma Biological Honors Society Beta Lambda Chapter.

T. M. 


\section{CONTENTS}

ACKNOWLEDGMENTS

Page

i

CONTENTS

CHAPTER I: INTRODUCTION 1

Plant Hormones and Signaling $\quad 1$

Cuscuta pentagona Biology 2

Phytophthora nicotianae Biology 3

Research Goals and Hypotheses $\quad 4$

CHAPTER II: MATERIALS AND METHODS 8

Cultivation and Preparation of Cuscuta pentagona and Tomato 8

Cultivation and Preparation of Phytophthora nicotianae $\quad 8$

$\begin{array}{ll}\text { Measurement of Salicylic Acid } & 8\end{array}$

$\begin{array}{ll}\text { Measurement of Chlorophyll } & 9\end{array}$

Experiment 1. SA Response of S. lycopersicum to Infestation by Multiple Parasites 9

Experiment 2: Artificial Elicitation of Salicylic Acid in C. pentagona 10

Experiment 3. Bridging Multiple Hosts by C. pentagona 12

CHAPTER III: RESULTS 13

Experiment 1: Individual and Coinfection by $C$. pentagona and $P$. nicotianae 13

Experiment 2: Artificial elicitation of salicylic acid in C. pentagona 13

Experiment 3: Bridging an Infected Host to an Uninfected Host via C. pentagona 14

$\begin{array}{ll}\text { CHAPTER IV: DISCUSSION } & 15\end{array}$

Salicylic Acid Response to Coinfection by C. pentagona and P. nicotianae 15

Artificial elicitation of salicylic acid in C. pentagona 17 


\section{CHAPTER I: INTRODUCTION}

\section{Plant Hormones and Signaling}

Plants exist in complex communities wherein they are frequently defending against attacks by parasites, herbivores, and pathogens. As a result of these constant assaults from enemies, plants have evolved a chemical defense system that allows them to not only protect themselves but communicate with other organisms in the community. Plant defense against pathogens and herbivory is mediated by several phytohormones. Jasmonic acid (JA), salicylic acid (SA), and ethylene are the three major hormones that signal for the synthesis of pathogenesis related proteins (Schweiger et al. 2014). Jasmonic acid is involved in defense against chewing herbivory and necrotrophic pathogens, salicylic acid mediates defense against penetrating herbivory, biotrophic pathogens, and abiotic stresses, and ethylene mediates interactions between salicylic acid and jasmonic acid responses (Chaman et al. 2003, Schweiger et al. 2014, Khan et al. 2016, Genzel et al. 2018). All three of these molecules can be volatilized: JA and SA are volatile when methylated, and ethylene is naturally volatile. As volatile compounds, all three hormones enable chemical communication between plants (Shulaev et al. 1997, Fung et al. 2004, Wu et al. 2008). Interplant communication has been documented to positively affect plant growth and defense reactions, and recent publications indicate that parasitic plants can enable the movement of secondary metabolites and proteins between their hosts (LeBlanc et al. 2013, Zhuang et al. 2018, Banerjee 2020).

Salicylic acid is a plant hormone involved in a variety of plant processes such as growth and defense. Salicylic acid is synthesized via two pathways, named the isochorismate synthase pathway and the phenylalanine ammonia lyase pathway, both of which use chorismate as a

precursor molecule (Dempsey et al. 2011, Lefevere et al. 2020). The isochorismate pathway has 
been observed to occur in the chloroplast in Arabidopsis species, tomato, and Nicotiana benthamiana (Metraux 2002, Fragniere et al. 2011); whereas in tobacco, synthesis of salicylic acid uses benzoic acid in the cytosol (Wildermuth et al. 2002, Dempsey et al. 2011). In tomato plants, salicylic acid has been observed as developing via the phenylalanine ammonia lyase pathway (Chen et al. 2009). Salicylic acid being synthesized in chloroplast in some plants has interesting implications for defense processes in non-photosynthetic plants, such as the parasite C. pentagona.

Cuscuta pentagona Biology

Cuscuta is a genus of obligate parasitic vines in the family Convolvulaceae, with 215 species found natively globally (McNeal et al. 2007a, Garcia et al. 2014). All species grow and wrap around a host plant and develop a modified organ called a haustorium (Lee 1992, Zhuk 1997). Haustoria penetrate the epithelium of plants to uptake water, sugars, and vital nutrients from the xylem and phloem of the host plant (Furuhashi et al. 2012, Olsen and Krause 2017). Uptake from host cells occurs via both apoplastic and symplastic pathways at the haustorial interface (Haupt et al. 2001). As holoparasitic plants, Cuscuta have lost the chloroplast as an organelle but maintain the plastid DNA (Braukmann et al. 2013). Cuscuta have been demonstrated to elicit both salicylic and jasmonic acid defenses, as well as transfer herbivoryinduced signals in hosts connected by Cuscuta vine networks (Runyon et al. 2010, Hettenhausen et al. 2017). Runyon et al. (2010) also provide evidence that the salicylic acid response after a second attack by Cuscuta is much stronger than during the initial infection. These previous results indicate that there is interaction between Cuscuta infestation and salicylic acid and that Cuscuta intake and transfer molecules across hosts. 
If salicylic acid is synthesized in the chloroplast, then the loss of the chloroplast may result in one of several outcomes in terms of Cuscuta's ability to produce salicylic acid. One possibility is that the Cuscuta may not produce salicylic acid on its own, rendering it vulnerable to herbivory and infection without a secondary source. A second possibility is that Cuscuta does not synthesize salicylic acid and does not require it as a defense hormone because another system has filled a similar role. Finally, Cuscuta may synthesize salicylic acid at a level that is less than in photosynthetic plants. If the Cuscuta are deficient in their salicylic acid content, they may take in salicylic acid from their hosts to elicit production of SA-induced defense response proteins to establish their immune response. If, however, Cuscuta are not observed to be deficient in salicylic acid, that may indicate that they utilize the phenylalanine ammonia lyase or another pathway to synthesize their own salicylic acid without need of chloroplasts. Intake of macromolecules is required for nutrients in the parasite, and it has been previously observed that the intake of molecules from a host is not selective, as viral particles have been observed moving through the haustorial interface (Mikona and Jelkmann 2010). Bidirectional movement has also been observed at the haustorial interface (Haupt et al. 2001). Therefore, if Cuscuta intake salicylic acid from one plant and do not use it, the salicylic acid may be transferred to another host.

\section{Phytophthora nicotianae Biology}

Cuscuta pentagona is a shoot-attacking parasite whereas the other parasite in this experimental system is a root pathogen. Phytophthora nicotianae is a generalist oomycete pathogen of plants that is of global concern (Barwell et al., 2020). As a pathogen, P. nicotianae releases chlamydospores resulting from asexual reproduction. These chlamydospores can eventually give rise to motile zoospores that chemotactically seek host roots and produce 
infection. Upon infecting a host, the spores germinate and develop cysts on the root surface to initiate disease (Hickman 1970, Hardham 2001). Infection by P. nicotianae leads to stem and root rot in the host, and eventual chlorosis of the leaves until the plant dies. When infecting Arabidopsis thaliana, P. nicotianae elicited a primarily jasmonic acid-based defense response, though some increase in salicylic acid was also observed in soybean as a response to related $P$. sojae (Dong et al. 2015, Kong et al. 2017). As a tomato pathogen, P. nicotianae has been somewhat studied in recent years, especially concerning ways to mediate the pathogenicity to hosts (La Spada et al. 2020), though there has been lesser focus on hormonal defenses of the tomato. There is evidence that $P$. nicotianae zoospore exudates modulate salicylic acid in Arabidopsis thaliana (Kong et al. 2017), and that salicylic acid mediated defenses are effective in reducing the severity of $P$. nicotianae infection (Benouaret and Goupil 2015, Wu et al. 2017, Wu et al. 2018). It is unclear if $P$. nicotianae will specifically elicit systemic acquired resistance mediated by salicylic acid, or induced systemic resistance mediated by jasmonic acid and how that response activates following host infestation by another parasite.

\section{Research Goals and Hypotheses}

Cuscuta pentagona's existence as a parasitic plant raises questions about how host plant defenses, specifically in this study salicylic acid, interact with it. One of the biosynthetic pathways of salicylic acid occurring in the chloroplast and Cuscuta's lack of chloroplast also presents an interesting dynamic. Does C. pentagona induce a salicylic acid response in its hosts, and will that response affect subsequent infection in other parts of the plant? How does $C$. pentagona produce salicylic acid if it needs to? Does it absorb salicylic acid from its hosts or generate its own independently, and if it absorbs salicylic acid from a host can it transfer salicylic acid between hosts? In an attempt to answer these questions, I performed three 
experiments investigating the impact of infection by a stem holoparasite, C. pentagona and infection by a root pathogen, $P$. nicotianae, on the salicylic acid responses of their host and of Cuscuta.

In our first experiment I hypothesize that $C$. pentagona and $P$. nicotianae, as parasites of tomato, will elicit systemic acquired resistance demonstrated by an increased concentration of salicylic acid and therefore induce a defensive response in a tomato host. To test this hypothesis, tomato plants were infested with C. pentagona, and P. nicotianae independently, or simultaneously. By the design of this experiment, the Cuscuta attaches to the host and begins its parasitism before the $P$. nicotianae, therefore I predict that on plants already infected with Cuscuta, if systemic acquired resistance is activated, a greater amount of salicylic acid will be observed in the coinfected tomatoes than in either of the singularly infected tomato groups. It was predicted that the intensity of the salicylic acid response would differ between the parts of the plant infested. (1) When infested by Cuscuta there will be a more intense salicylic acid response in the shoot, (2) when infested by $P$. nicotianae there will be a more intense salicylic acid response in the roots, and (3) when both are present the relative increase in concentration of salicylic acid will be greater in both leaves and roots than when infested by only one attacker. Subsequently, I hypothesize that Cuscuta infecting tomatoes coinfected by $P$. nicotianae, will have increased concentration of salicylic acid relative to those vines attached to tomatoes as their only challenger.

If Cuscuta is deficient in the production of salicylic acid because it lacks chloroplast then I hypothesize that Cuscuta can acquire salicylic acid synthesized in its hosts to develop its own defense. Cuscuta being an obligate parasite, presents a problem for determining from which organism the salicylic acid originates in the host-parasite pair. Cuscuta seedlings can persist 
unattached for several days while seeking out a new host, subsisting on nutrient stored in the seed and a vestigial root that is speculated to allow for very limited carbon movement (Sherman et al. 2008). During this brief period, Experiment 2 tested whether Cuscuta can produce salicylic acid independent of its host. Cuscuta was grown from seed alone or with a tomato host and remained undamaged, exposed to physical damage via penetration via needle to simulate penetrating herbivory (Hettenhausen et al. 2017), or exposed to methyl salicylate. Plants attached to a host were predicted to have a higher concentration of salicylic acid than unattached seedlings. I then predict, relative to the untreated plants, that exposure to methyl salicylate will produce the greatest salicylic acid response as it can be metabolized to salicylic acid. I further predict that damage by needle will produce an increased salicylic acid response, but not to the extent of methyl salicylate, because this will physically mimic penetration by an herbivorous insect but will lack the chemical component.

Cuscuta can transfer several molecules between hosts, including DNA, viruses, and various herbivory-induced signals (Mikona and Jelkmann 2010, Zhang et al. 2014, Hettenhausen et al. 2017). This raises the possibility that phytohormones such as salicylic acid can also move from one host to another affecting physiological changes in secondary hosts. In Experiment 3, I tested the hypothesis that Cuscuta can intake salicylic acid from one host and transmit those molecules to another host, by quantifying salicylic acid concentration in $C$. pentagona bridging a pair of hosts and its concentrations in leaves and roots of the hosts. In half the replicate pairs the primary host was challenged with $P$. nicotianae. If defense molecules are transferred from one host to another via a Cuscuta bridge, I predicted an elevated salicylic acid content in a secondary plant attached to an infected primary host compared to one attached to a non-infected primary 
host, resulting from either the direct transfer of salicylic acid or an increased response from the secondary host's own tissue. 


\section{CHAPTER II: MATERIALS AND METHODS}

\section{Cultivation and Preparation of Cuscuta pentagona and Tomato}

Cuscuta pentagona seeds were treated with concentrated sulfuric acid for 1 hour and rinsed with water prior to planting. The seed was extracted from the seed coat and planted in the media being used for each experiment as described in the appropriate section. Culture hosts (tomatoes, Solanum lycopersicum) were grown from seed in PRO-MIX® premium all-purpose potting mix. Plants were thinned to 1 per pot and fertilized with Schultz® tomato food (17-18$28 \mathrm{~N}-\mathrm{P}-\mathrm{K}$ ) weekly at a concentration of $1.25 \mathrm{~g} / \mathrm{L}$. The tomato plants were watered everyday to soil saturation.

\section{Cultivation and preparation of Phytophthora nicotianae}

Phytophthora nicotianae was obtained from ATCC® and cultured on a V8 tomato juiceagar plate. For inoculation, plugs of $P$. nicotianae oospores from the plates were placed in petri dishes filled with non-sterile soil extract. The non-sterile soil extract was prepared by the addition $10 \mathrm{~g}$ of non-sterile soil to $500 \mathrm{~mL}$ sterile water followed by filtration of the water via filter paper. The petri dishes were then incubated under continuous light for 72 hours or until a minimum of 50 oospores were counted in $50 \mu \mathrm{L}$ of the inoculum on a cytometer under the microscope (Chee and Newhook 1966). At that point, an amount of P. nicotianae inoculum was added to the designated plants, as described for each experiment below.

Measurement of Salicylic Acid

Salicylic acid content was measured in all cases by homogenizing tissue after freezing at $-80{ }^{\circ} \mathrm{C} .1 \mathrm{~mL}$ of DI water was added to each of the samples, shaken, and spun at $14000 \mathrm{rpm}$ for 10 minutes. The liquid phase was then removed and mixed with $3 \mathrm{~mL}$ freshly made $0.1 \% \mathrm{FeCl}_{3}$ solution. The samples were then measured using spectrophotometry at $540 \mathrm{~nm}$. The absorbance 
of the samples was compared against standard curves generated from 0, 10, 25, 50, 100, 200, 300,400 , and $500 \mu \mathrm{g} / \mathrm{mL}$ solutions of salicylic acid to estimate the concentration of salicylic acid in the tomato and Cuscuta samples. Values were divided by the mass of the extracted sample and expressed as $\mu \mathrm{g} / \mathrm{ml} / \mathrm{g}$ of tissue.

Measurement of Chlorophyll

After harvesting leaves nearest to the infestation site by Cuscuta pentagon from the tomato plants, the next nearest leaf was removed and frozen at $-80{ }^{\circ} \mathrm{C}$ for chlorophyll extraction. Chlorophyll was extracted by soaking the leaves in $7 \mathrm{~mL}$ of DMSO and incubating in a water bath at $65{ }^{\circ} \mathrm{C}$ for one hour. After removal from the water an additional $3 \mathrm{~mL}$ of DMSO was added to the containers. The solutions were measured three times in a spectrophotometer at 663 and $645 \mathrm{~nm}$. The average of the three spectrophotometer trials for each wavelength was used, in conjunction with Arnon's equations (Arnon 1949, Hiscox and Israelstam 1979), to calculate the concentration of chlorophylls a and b, as well as the total chlorophyll concentration. Experiment 1. SA Response of S. lycopersicum to Infestation by Multiple Parasites

Solanum lycopersicum (Tomato) seeds were thinned to 1 plant per conical pot, approximately $4 \mathrm{~cm}$ in diameter and $14 \mathrm{~cm}$ tall, and randomly assigned to one of four treatments that were combinations of $C$. pentagona (no/yes) and $P$. nicotianae (no/yes; Fig. 1). Upon the appearance of the first true leaves, Cuscuta seeds were planted next to each of the twenty experimental tomatoes designated for infestation. The Cuscuta germinated and attached usually between 4 and 7 days after planting. When the first Cuscuta had attached, other Cuscuta sprouts were pulled from the pots and the tomatoes designated for infection were inoculated with $P$. nicotianae oospores. Cuscuta plants were considered attached after one full loop was observed around the stem of a host, and the margins of at least one haustoria were observed. The 
inoculation was done by pipetting $125 \mu \mathrm{L}$ of inoculum, containing approximately one spore per $\mu \mathrm{L}$, into the soil near the base of the tomato. Seventy-two hours after infection with $P$. nicotianae, the terminal blade of the first true leaves, and the upper most $2.5 \mathrm{~cm}$ of the root system were harvested from each tomato plant for salicylic acid quantification. The terminal blade of the second true leaf was collected for chlorophyll quantification. All Cuscuta tissue was also harvested from each plant. The tissues were immediately weighed and frozen at $-80{ }^{\circ} \mathrm{C}$. The salicylic acid was quantified using the $\mathrm{FeCl}_{3}$ assay outlined. The salicylic acid concentration $(\mu \mathrm{g} / \mathrm{ml} / \mathrm{mg})$ in leaves and roots of tomato were transformed by a $\log _{10}$ transformation to meet assumptions of normality and homogeneity of variance. These data were analyzed using a multivariate analysis of variance (PROC GLM, SAS 9.4) with Cuscuta presence, $P$. nicotianae challenge, and the interaction as effects. The impact of $P$. nicotianae challenge to the host plant on salicylic acid concentration of the Cuscuta was analyzed using PROC GLM in SAS 9.4.

Experiment 2. Artificial Elicitation of Salicylic Acid in C. pentagona.

Thirty tomato plants were again grown and infested by Cuscuta as described in Experiment 1. Tomato and Cuscuta replicates will be described as pairs in this experiment. Each pair was randomly assigned to a treatment. Ten plant pairs grew untreated as control, ten pairs were treated with artificial damage to the Cuscuta by a needle, and ten pairs were exposed to methyl salicylate (MeSA) vapor in an airtight plexiglass container at the same time (Figure 2). Plants undergoing treatment were introduced to treatment after successful attachment by Cuscuta. The Cuscuta were artificially damaged using a needle to penetrate the Cuscuta epithelium 3 times on the surface opposite the haustoria to simulate damage by penetrating herbivory. The MeSA plants were placed in a plexiglass box, 5 per box, randomly situated 
throughout, a test tube containing $5 \mathrm{~mL}$ of MeSA was added to the box and allowed to evaporate naturally. Those plants sealed in the boxes were separated spatially from the other plants to prevent any gaseous MeSA from encountering those treatments. MeSA treatments were applied collectively. 72 hours after initial exposure to treatment, the above-ground biomass of the tomatoes and the Cuscuta were harvested for measurement. The biomass was weighed and frozen at $-80{ }^{\circ} \mathrm{C}$ until measurement.

Concurrent with the tomato-Cuscuta pairs, 30 Cuscuta seeds were germinated in 3 petri dishes sealed in parafilm, 1 dish per treatment. Each of the 3 petri dishes was subjected to the same type of treatment as the pairs (Figure 2). 72 hours after germination by the first seed, all the required Cuscuta had germinated and grown sufficiently for treatment. The parafilm was removed from the petri dishes, ten plants were untreated for control purposes. Ten plants were pierced 3 times using a needle at the portion farthest from the seed. The final ten plants were exposed to MeSA vapor sourced from $100 \mu \mathrm{L}$ of liquid MeSA in a tube cap. Once introduced to treatment the dishes were resealed with parafilm and allowed to grow for another 72 hours. These Cuscuta were weighed and frozen until measurement.

After thawing, the tissue was homogenized, and the salicylic acid was quantified using the $\mathrm{FeCl}_{3}$ assay outlined. The salicylic acid concentration $(\mu \mathrm{g} / \mathrm{ml} / \mathrm{g})$ in tomato and $\mathrm{Cuscuta}$ were transformed by a $\log _{10}$ transformation to meet assumptions of normality and homogeneity of variance. These data were analyzed using a one-way analysis of variance (PROC GLM, SAS 9.4) using control, the MeSA, or needle damage as treatments.

Experiment 3. Bridging Multiple Hosts by C. pentagona 
Forty tomato plants were grown in $5 \mathrm{~cm} \mathrm{x} 5 \mathrm{~cm} \mathrm{x} 30.5 \mathrm{~cm}$ pots. 20 of the tomatoes were randomly assigned to be either infested by both Cuscuta and P. nicotianae, or only infested by Cuscuta; these 20 plants are the primary plants. The randomly assigned plants were later paired with an uninfested tomato plant of approximately equivalent size; these 20 plants are the secondary plants (Figure 3). Infestation by Cuscuta occurred as described in the previous experiments. After attachment to the primary plants, the Cuscuta grew until it reached the secondary plant. The vine of sufficient length was guided to the secondary plant for attachment. When attached to the secondary plants, $300 \mu \mathrm{L}$ of $P$. nicotianae inoculum were added to the soil at the base of the primary tomato plant. 72 hours after inoculation with $P$. nicotianae, the terminal blade of the leaf nearest the initial attachment site of Cuscuta on both plants, the top centimeter of the roots, the $5 \mathrm{~cm}$ of Cuscuta at the initial attachment sites on both plants and a 5 $\mathrm{cm}$ section bridging the two plants were all taken for salicylic acid quantification with $\mathrm{FeCl}_{3}$. The terminal blade of the second nearest leaf to the Cuscuta attachment site was collected for chlorophyll measurement. The salicylic acid concentration $(\mu \mathrm{g} / \mathrm{ml} / \mathrm{g})$ in leaves and roots of tomato were transformed by a $\log _{10}$ transformation to meet assumptions of normality and homogeneity of variance. These data were analyzed using a repeated measures analysis of variance (PROC GLM, SAS 9.4) with primary or secondary plant as the repeated measure, leaf or root as level of response, and $P$. nicotianae challenge as the treatment. The impact of $P$. nicotianae challenge to the host plant on salicylic acid concentration of the Cuscuta was analyzed using PROC GLM in SAS 9.4. 


\section{CHAPTER III: RESULTS}

The standard curves used to estimate the salicylic acid content of the tomato and Cuscuta samples for each experiment consistently yielded linear results with a correlation coefficient minimum of 0.9893 (Figure 4).

\section{Experiment 1. Individual and Coinfection by C. pentagona and P. nicotianae}

A multivariate analysis of variance performed on the salicylic acid concentration in tomato plant leaves and roots revealed no significant effect of $C$. pentagona (Table 1). However, the effect of $P$. nicotianae was significant and this was expressed in the roots (Table 1). $P$. nicotianae decreased the salicylic acid content (Figure 5). The interaction of pathogen challenge and Cuscuta in the MANOVA was not significant (Table 1), indicating that Cuscuta does not alter the tomato's salicylic acid response to the root pathogen.

Despite transformation, the data for salicylic acid concentration in Cuscuta tissue did not meet assumptions of normality and homogeneity of variance. Using the interquartile range of the data, I identified two outliers (Vinutha et al. 2018). When these two values were removed, no transformation was required and $P$. nicotianae challenge to host plants significantly affected $\operatorname{Cuscuta}\left(F_{1,14}=26.85, P=0.0001 ;\right.$ Figure 6$)$. The salicylic acid concentration was doubled in Cuscuta attached to tomatoes coinfected by P. nicotianae relative to Cuscuta that was the sole attacker of the tomato hosts.

Multivariate analysis of variance of log-transformed chlorophyll A and chlorophyll B showed no significant effects due to Cuscuta, $P$. nicotianae, or the interaction $(P>0.05$ for all). Experiment 2. Artificial Elicitation of Salicylic Acid in C. pentagona

In the tomato hosts, salicylic acid content of leaves was higher in the tomatoes exposed to methyl salicylate vapors than in control plants $(P=0.055)$, but no other pair-wise comparisons 
were near significant $(P>0.05$ for all; Figure 8$)$. Whether it was on or off a tomato plant did not significantly affect the salicylic acid content of the Cuscuta plant $\left(F_{1,52}=1.06, P=0.308\right)$ and treatment was only marginally non-significant $\left(F_{2,52}=2.80, P=0.070\right)$. Cuscuta artificially damaged had lower levels of salicylic acid than controls $(P=0.056$; Figure 9$)$. Experiment 3. Bridging an Infected Host to an Uninfected Host via C. pentagona

Tomato leaves exhibited greater salicylic acid concentration than roots (Pillai's Trace $\left.=0.998, F_{2,12}=3888.4, P<0.0001\right)$. These two parts tended to respond to $P$. nicotianae challenge differently (Pillai's Trace $=0.347, F_{2,12}=3.19, P=0.0773$ ) but this response differed between the primary plant, which was challenged directly, and the secondary plant, which was connected to the primary plant by a Cuscuta bridge (Pillai's Trace $=0.472, F_{2,12}=5.36, P=$ 0.0217). The only significant response was in the roots of the secondary plant, which exhibited depressed salicylic acid concentration when the neighbor was challenged $(P=0.0051$; Fig. 10$)$.

Treatment of the primary host did not alter the salicylic acid content of Cuscuta connecting the primary and secondary host (Pillai's Trace $=0.065, F_{2,10}=0.35, P=0.7132$ ) however, the three sections exhibited different concentrations (Pillai's Trace $=0.672, F_{2,10}=$ $10.25, P=0.0038)$. The Cuscuta segments immediately attached to the tomato hosts were not significantly different from each other. The segment of Cuscuta that was not attached to either host but spanned the two host plants had diminished salicylic acid content relative to either connection points (Table 4; Fig. 11).

There was a significant difference in log-transformed chlorophyll a and b concentration between primary and secondary plants (Pillai's Trace $=0.429, F_{2,13}=4.89, P=0.0261$ ). The effect of $P$. nicotianae, however, does not explain the difference between the primary and secondary plants (Pillai's Trace $=0.199, F_{2,13}=1.61, P=0.2366$ ). 


\section{CHAPTER IV: DISCUSSION}

Salicylic Acid Response to Coinfection by C. pentagona and P. nicotianae

To investigate the salicylic acid interactions occurring between a tomato host, the shoot parasite $C$. pentagona, and the root pathogen $P$. nicotianae, I set out to test the hypothesis that tomatoes exhibit systemic acquired resistance to these agents. I predicted that the salicylic acid content of tomato plant would increase when infected by either $C$. pentagona or $P$. nicotianae. If Cuscuta primes the plant against future attacks I predicted higher levels of salicylic acid in the tomato host when subject to $P$. nicotianae after infestation by Cuscuta. I further predicted that the salicylic acid changes of the host would be observable in C. pentagona as a similar increase in salicylic acid when infesting a $P$. nicotianae infected host relative to an uninfected host. Our results contradict our prediction that $P$. nicotianae would increase salicylic acid; I observed that the below ground biomass had a significant decrease in the salicylic acid content when exposed to $P$. nicotianae and the aboveground biomass did not respond to either challenge.

The decrease in salicylic acid may suggest that defense against $P$. nicotianae is a jasmonic acid-based response. Previous work looking at the hormonal defense processes of plants provides evidence for an antagonistic relationship between salicylic and jasmonic acid (Spoel et al. 2003). When a plant is parasitized, or fed upon, a decrease in salicylic acid may suggest an increase in jasmonic acid, such as is seen in response to the caterpillar Heliothis virescens (Schweiger et al. 2014) or the fungal pathogen Pseudomonas syringae (Devadas et al. 2002). The antagonism between salicylic and jasmonic acid helps the plants to defend against specific types of pathogens each by signaling for the transcription of defense protein related to 
the type of defense they deal with. The jasmonic acid response is indicative of infection by a necrotrophic pathogen (Brenya et al. 2020, Narayanan et al. 2020), and P. nicotianae is such.

The lack of apparent change in the salicylic acid concentration of above ground biomass indicates that the response to this root pathogen is not broadly systemic as might be expected from a salicylic acid response. A link between salicylic acid and systemic acquired resistance has been postulated for some time (Gaffney et al. 1993, Mauch-Mani and Metraux 1998, Klessig et al. 2018) and there is a body of work supporting salicylic acid as a trigger for systemic acquired resistance, but not necessarily as the mobile signal in the response (Li et al. 1999, Anand et al. 2008). Cuscuta itself did not elicit a local response as I expected. Previous work as well as our own preliminary unreported data suggest that the salicylic acid response to $C$. pentagona peaks at approximately 60-72 hours after attachment (Runyon et al. 2010), though published data pertaining to timing of salicylic acid spikes are limited. Our results are not consistent with previous work that showed salicylic acid and jasmonic acid are increased sequentially as a response to C. pentagona infestation (Runyon et al. 2010). In Runyon et al. (2010), salicylic acid is demonstrated to peak around 60 hours and decrease to 120 hours and is preceded by a spike in jasmonic acid. In our experiments, samples were harvested 72 hours after treatment based on preliminary unreported data that aligns well with the approximate time of the Runyon study.

The non-systemic nature of the observed changes is supported by our findings from the salicylic acid measurements from the Cuscuta. In addition to predicting an increase in salicylic acid systemically in the tomato infected with $P$. nicotianae, I predicted this increase in the host would lead to an increase in salicylic acid within the Cuscuta, especially if the holoparasite does not produce its own salicylic acid. That the Cuscuta had increased salicylic acid when attached 
to tomatoes infected by $P$. nicotianae was consistent with our initial predictions but the proposed mechanism for this increase was not. In fact, the results are counter intuitive considering that the tomato leaf did not exhibit increased concentrations. The increase in salicylic acid in the Cuscuta without a concurrent increase in the salicylic acid content of the tomatoes seemingly rejects our hypothesis that Cuscuta is incapable of producing its own salicylic acid. Further biochemical testing would be needed to ascertain the origins of this salicylic acid in the Cuscuta. Why the change is observed in Cuscuta on coinfected tomatoes is unclear and raises interesting questions about how coinfecting parasites interact via the host. The observed increase in salicylic acid could be caused by several physiological responses, such as a response to abiotic stress if the P. nicotianae created a nutrient deficiency in the tomato and therefore also in the Cuscuta. Though primarily involved in plant defense against abiotic stress and biotrophic disease, salicylic acid is also involved in transpiration and ion movement (Manthe et al. 1992, Vlot et al. 2009). One potential explanation for Cuscuta's increased salicylic acid on infected hosts is that attachment to a nutrient stressed host increases Cuscuta's need to apply more resources to transpiration and intake of nutrients than for an undamaged Cuscuta parasitizing the host (Clayson et al. 2014). Further testing would be needed to tease out the mechanisms causing Cuscuta to have elevated salicylic acid. Based on our results, C. pentagona does not prime its host's salicylic acid response for future attack, but it does respond to changes in the host's salicylic acid levels even if that change occurs in the host's roots.

\section{Artificial Elicitation of Salicylic Acid in C. pentagona}

By artificially damaging $C$. pentagona while attached and unattached to a tomato host, I attempted to elucidate whether $C$. pentagona is capable of producing its own salicylic acid or not. C. pentagona 's lack of chloroplast led me to hypothesize that these plants would be 
deficient in salicylic acid, because one major pathway for salicylic acid biosynthesis occurs in the chloroplast. To test our hypothesis, I challenged Cuscuta that was attached to hosts and grown alone with artificial damage and chemical means and then measured salicylic acid in both tomato and Cuscuta tissue. The tomato plants experienced increased salicylic acid content in the presence of methyl salicylate. This result was expected because methyl salicylate forms a volatile form of salicylic acid that allows for interplant signaling via airborne transmission of salicylic acid to enable defense responses in neighboring plants (Shulaev et al. 1997, Deng et al. 2017). Surprisingly, when the Cuscuta was artificially damaged, the tomatoes also tended to experience increased salicylic acid content, although this was not significant. While this difference is within the range expected due to chance alone, the trend suggests that communication between Cuscuta and tomato may occur when the Cuscuta is damaged, and damage to the parasite elicits some increase in salicylic acid in the host. Increased salicylic acid in the host when Cuscuta is damaged could occur if the tomato recognizes Cuscuta as an extension of itself and sinks resources into the Cuscuta. Host manipulation by Cuscuta has also been observed in otherwise healthy plants with respect to tomato growth and volatile phytochemical emissions (Johnson et al. 2016). Given that two-way movement occurs at the haustorial interface (Haupt et al. 2001, Hettenhausen et al. 2017) and that Cuscuta manipulates it host's response (Shahid et al. 2018), a challenge to Cuscuta could trigger some response in the host. However, further, and more specific testing is needed to elucidate that interaction. Also, further study may also examine the recognition of Cuscuta as a parasite by tomato and how that effects the translocation of macromolecules between host and parasite.

I predicted that artificial induction of salicylic acid by physical (needle damage) and chemical means (methyl salicylate) would increase salicylic acid in Cuscuta attached to a host, 
relative to Cuscuta grown without hosts, because our operating hypothesis for this experiment was that the host is the source of salicylic acid for Cuscuta. The Cuscuta data, however, indicate that the plants without any treatment had the greatest salicylic acid content. I reject the hypothesis that Cuscuta is deficient in salicylic acid because of the lack of chloroplast. Cuscuta seems to have an alternate method of generating salicylic acid, perhaps via upregulation of the phenylalanine ammonia lyase pathway or the continued expression and integration of the isochorismate pathway proteins into another membrane within the cell (Chen et al. 2009, Kim and Hwang 2014). This opens the door for potentially interesting work looking at Cuscuta transcription of the chloroplast plastid genome still observed in the genus (McNeal et al. 2007b, Krause 2011).

Transfer of Salicylic Acid from an Infected Host to an Uninfected Host

Based on previous studies indicating the transfer of defense molecules via Cuscuta australis (Hettenhausen et al. 2017, Zhuang et al. 2018) I predicted that Cuscuta would transfer salicylic acid from one host to another in greater amounts if a primary plant was infected by $P$. nicotianae relative to plants that were not. I failed to find evidence that salicylic acid moves from one host to another via Cuscuta, however I did find some evidence that may support the intake of salicylic acid by the Cuscuta from the host. The tissue taken from Cuscuta at the attachment sites to the primary host and the secondary host tomato had increased salicylic acid content relative to the tissue that bridged the two host plants. Though the lack of apparent increase of salicylic acid in the host tissue it may also be that $C$. pentagona is producing its own salicylic acid. If salicylic acid were moving across this section, I would expect to see a somewhat uniform salicylic acid content or declining content from the point of attachment to the primary host to the attachment to the secondary host. The increased salicylic acid in haustoria and nearby 
tissue of Cuscuta may suggest that salicylic acid plays some role in the penetration and continued infection of the host plant (Furuhashi et al. 2011, Furuhashi et al. 2012), or it may be utilized at the site of intake (Furuhashi et al. 2012) and the downstream proteins produced in SAsignaled responses are transported between hosts.

Regarding the hosts' salicylic acid content, our results for the bridging experiment were not consistent with the results described in our coinfection experiment, which showed a decreased SA response in plant roots infected by P. nicotianae. In Experiment 3, P. nicotianae decreased salicylic acid in the uninfected secondary plant but had no effect on the primary plant. In this experiment, all the plants were several days older than in the coinfection experiment, as such hormonal changes in the tissue that was observed in the coinfection experiment may have faded by the time tissue was harvested in the bridging experiment. Alternatively, the older plants may have been more resistant to infection and the spore then failed to infect the roots properly, though the significant effect in the secondary infected roots suggests failure to infect was unlikely. The only significant effect observed was a decreased amount of salicylic acid in the roots of the secondary plant in the pairs infected with P. nicotianae. Whatever signal mobilized across the Cuscuta may have increased jasmonic acid in the roots of the secondary host as I expect happens in the tomato root tissue from the coinfection experiment previously described. Taken together with the lack of salicylic acid decrease in the primary infected plants, if infection was successful in the primary plant and by time of measurement they had recovered, signals transferred from primary to secondary plant may explain the decreased salicylic acid content in the secondary roots. Further testing would be needed to ascertain if this is the case, testing mRNA transcripts of protein responses triggered by a jasmonic acid response in a similar experimental set up would confirm a jasmonic acid response to $P$. nicotianae, and isolation of 
those transcripts following a gradient across bridging Cuscuta may identify a mobile signal for jasmonic acid defense response.

Salicylic acid interaction of C. pentagona and its tomato host

The interaction of parasites and hosts is a critically important area of research for agricultural, ecological and conservation purposes. Frequently, research examining host-parasite systems focuses on a binary system of one host and one parasite, however, wild systems are never so simple, and conclusions drawn from such research, while valuable, are incomplete. This study provides insight regarding the intake, utilization, and communication of salicylic acid between tomato plants and $C$. pentagona parasitizing them. I provide explicit evidence that $C$. pentagona is capable of producing its own salicylic acid, it interacts with its host when the host is infected by other pathogen via salicylic acid, and that salicylic acid is not the mobile signal for the communication, documented by previous work, between hosts bridged by $C$. pentagona. Transcriptomic work focusing on downstream proteins of salicylic and jasmonic acid-based defense responses in Cuscuta and its hosts would improve understanding of how this novel parasite interacts with its hosts' defenses enable agricultural treatment of the parasite and deepen understanding of its role in ecosystems for ecological and conservation goals. 


\section{CHAPTER V: RELEVANCE AND CONCLUSION}

All organisms exist in complicated communities, frequently interacting with more than one antagonistic entity at a time. Salicylic acid is one of the essential plant defense hormones that mediates the interactions of plants and parasites in several ways. When one of those parasites, however, is another plant, more common means of plant defense offer interesting and important areas of research. Cuscuta species are agriculturally significant, causing reduction in yields of several economically important crops, such as tomato and carrot (Albert et al. 2008);

they are ecologically significant as parasites, helping to maintain diversity (Ridenour et al. 2014), and have potential as biocontrol agents of invasive plants because as a genus there is an endemic species in many places throughout the world (Shen et al. 2005, Wu et al. 2013). Understanding the molecular and ecological aspects of Cuscuta infestations will benefit both agricultural interests looking to control a pest, and conservation interests trying to restrict growth of nonnative species and restore native habitats. This work focuses on the interactions of salicylic acid specifically to elucidate how Cuscuta interacts with its hosts and raises questions that may guide future research in the area. 


\section{REFERENCES}

Albert, M., X. M. Belastegui-Macadam, M. Bleischwitz, and R. Kaldenhoff. 2008. Cuscuta spp: Parasitic Plants in the Spotlight of Plant Physiology, Economy and Ecology. Progress in Botany 69:267-277.

Anand, A., S. R. Uppalapati, C. M. Ryu, S. N. Allen, L. Kang, Y. H. Tang, and K. S. Mysore. 2008. Salicylic Acid And Systemic Acquired Resistance Play A Role In Attenuating Crown Gall Disease Caused By Agrobacterium tumefaciens. Plant Physiolology 146:703715.

Arnon, D. I. 1949. Copper Enzymes In Isolated Chloroplasts - Polyphenoloxidase In BetaVulgaris. Plant Physiolology 24:1-15.

Banerjee, A. 2020. Inter-Plant Communication Via Parasitic Bridging. Journal of Experimental Botany 71:749-750.

Barwell, L. J., A. Perez-Sierra, B. Henricot, A. Harris, T. I. Burgess, G. Hardy, P. Scott, N. Williams, D. E. L. Cooke, S. Green, D. S. Chapman, and B. V. Purse. 2020. Evolutionary Trait-Based Approaches For Predicting Future Global Impacts Of Plant Pathogens In The Genus Phytophthora. Journal of Applied Ecology 58:718-730.

Benouaret, R., and P. Goupil. 2015. Grape Marc Extract-Induced Defense Reactions and Protection against Phytophthora parasitica Are Impaired in NahG Tobacco Plants. Journal of Agricultural and Food Chemistry 63:6653-6659. 
Braukmann, T., M. Kuzmina, and S. Stefanovic. 2013. Plastid Genome Evolution Across The Genus Cuscuta (Convolvulaceae): Two Clades Within Subgenus Grammica Exhibit Extensive Gene Loss. Journal of Experimental Botany 64:977-989.

Brenya, E., Z. H. Chen, D. Tissue, A. Papanicolaou, and C. I. Cazzonelli. 2020. Prior Exposure Of Arabidopsis Seedlings To Mechanical Stress Heightens Jasmonic Acid-Mediated Defense Against Necrotrophic Pathogens. BMC Plant Biology 20:548-564.

Chaman, M. E., S. V. Copaja, and V. H. Argandona. 2003. Relationships Between Salicylic Acid Content, Phenylalanine Ammonia-Lyase (Pal) Activity, And Resistance Of Barley To Aphid Infestation. Journal of Agricultural and Food Chemistry 51:2227-2231.

Chee, K. H., and F. J. Newhook. 1966. Relationship Of Micro-Organisms To Sporulation Of Phytophthora cinnamomi Rands. New Zealand Journal of Agricultural Research 9:32-43.

Chen, Z., Z. Zheng, J. Huang, Z. Lai, and B. Fan. 2009. Biosynthesis Of Salicylic Acid In Plants. Plant Signaling and Behavior 4:493-496.

Clayson, C., I. Garcia-Ruiz, and M. Costea. 2014. Diversity, Evolution, And Function Of Stomata Bearing Structures In Cuscuta (Dodders, Convolvulaceae): From Extrafloral Nectar Secretion To Transpiration In Arid Conditions. Perspectives in Plant Ecology, Evolution, and Systematics 16:310-321.

Dempsey, D. M. A., A. C. Vlot, M. C. Wildermuth, and D. F. Klessig. 2011. Salicylic Acid Biosynthesis And Metabolism. The Arabidopsis Book 9:24. 
Deng, W. W., R. Wang, T. Yang, L. Jiang, and Z. Z. Zhang. 2017. Functional Characterization Of Salicylic Acid Carboxyl Methyltransferase From Camellia sinensis, Providing The Aroma Compound Of Methyl Salicylate During The Withering Process Of White Tea. Journal of Agricultural and Food Chemistry 65:11036-11045.

Devadas, S. K., A. Enyedi, and R. Raina. 2002. The Arabidopsis Hrl1 Mutation Reveals Novel Overlapping Roles For Salicylic Acid, Jasmonic Acid And Ethylene Signalling In Cell Death And Defence Against Pathogens. Plant Journal 30:467-480.

Dong, L., Y. Cheng, J. Wu, Q. Cheng, W. Li, S. Fan, L. Jiang, Z. Xu, F. Kong, D. Zhang, P. Xu, and S. Zhang. 2015. Overexpression Of Gmerf5, A New Member Of The Soybean Ear Motif-Containing Erf Transcription Factor, Enhances Resistance To Phytophthora sojae In Soybean. Journal of Experimental Botany 66:2635-2647.

Fragniere, C., M. Serrano, E. Abou-Mansour, J. P. Metraux, and F. L'Haridon. 2011. Salicylic Acid And Its Location In Response To Biotic And Abiotic Stress. FEBS Letters 585:1847-1852.

Fung, R. W. M., C. Y. Wang, D. L. Smith, K. C. Gross, and M. S. Tian. 2004. MeSA And MeJA Increase Steady-State Transcript Levels Of Alternative Oxidase And Resistance Against Chilling Injury In Sweet Peppers (Capsicum anпиum L.). Plant Science 166:711-719.

Furuhashi, T., L. Fragner, K. Furuhashi, L. Valledor, X. Sun, and W. Weckwerth. 2012. Metabolite Changes With Induction Of Cuscuta Haustorium And Translocation From Host Plants. Journal of Plant Interactions 7:84-93. 
Furuhashi, T., K. Furuhashi, and W. Weckwerth. 2011. The Parasitic Mechanism Of The Holostemparasitic Plant Cuscuta. Journal of Plant Interactions 6:207-219.

Gaffney, T., L. Friedrich, B. Vernooij, D. Negrotto, G. Nye, S. Uknes, E. Ward, H. Kessmann, and J. Ryals. 1993. Requirement Of Salicylic-Acid For The Induction Of Systemic Acquired-Resistance. Science 261:754-756.

Garcia, M. A., M. Costea, M. Kuzmina, and S. Stefanovic. 2014. Phylogeny, Character Evolution, And Biogeography Of Cuscuta (Dodders; Convolvulaceae) Inferred From Coding Plastid And Nuclear Sequences. American Journal of Botany 101:670-690.

Genzel, F., P. Franken, K. Witzel, and R. Grosch. 2018. Systemic Induction Of Salicylic AcidRelated Plant Defences In Potato In Response To Rhizoctonia solani Ag3pt. Plant Pathology 67:337-348.

Hardham, A. R. 2001. The Cell Biology Behind Phytophthora Pathogenicity. Australas. Plant Pathology 30:91-98.

Haupt, S., K. J. Oparka, N. Sauer, and S. Neumann. 2001. Macromolecular Trafficking Between Nicotiana Tabacum And The Holoparasite Cuscuta reflexa. Journal of Experimental Botany 52:173-177.

Hettenhausen, C., J. Li, H. Zhuang, H. Sun, Y. Xu, J. Qi, J. Zhang, Y. Lei, Y. Qin, G. Sun, L. Wang, I. T. Baldwin, and J. Wu. 2017. Stem Parasitic Plant Cuscuta australis (Dodder) Transfers Herbivory-Induced Signals Among Plants. Proceedings of the National Academy of Sciences of the United States of America 114:6703-6709. 
Hickman, C. J. 1970. Biology Of Phytophthora Zoospores. Phytopathology 60:1128-1135.

Hiscox, J. D., and G. F. Israelstam. 1979. Method For The Extraction Of Chlorophyll From Leaf Tissue Without Maceration. Canadian Journal of Botany 57:1332-1334.

Johnson, B. I., C. M. De Moraes, and M. C. Mescher. 2016. Manipulation Of Light Spectral Quality Disrupts Host Location And Attachment By Parasitic Plants In The Genus Cuscuta. Journal of Applied Ecology 53:794-803.

Khan, G. A., E. Vogiatzaki, G. Glauser, and Y. Poirier. 2016. Phosphate Deficiency Induces the Jasmonate Pathway and Enhances Resistance to Insect Herbivory. Plant Physiology 171:632-644.

Kim, D. S., and B. K. Hwang. 2014. An Important Role Of The Pepper Phenylalanine AmmoniaLyase Gene (Pal1) In Salicylic Acid-Dependent Signalling Of The Defence Response To Microbial Pathogens. Journal of Experimental Botany 65:2295-2306.

Klessig, D. F., H. W. Choi, and D. A. Dempsey. 2018. Systemic Acquired Resistance and Salicylic Acid: Past, Present, and Future. Molecular Plant-Microbe Interactions 31:871888.

Kong, P., J. M. McDowell, and C. X. Hong. 2017. Zoospore Exudates From Phytophthora nicotianae Affect Immune Responses In Arabidopsis. PLoS One 12:12.

Krause, K. 2011. Piecing Together The Puzzle Of Parasitic Plant Plastome Evolution. Planta 234:647-656. 
La Spada, F., C. Stracquadanio, M. Riolo, A. Pane, and S. O. Cacciola. 2020. Trichoderma Counteracts The Challenge Of Phytophthora nicotianae Infections On Tomato By Modulating Plant Defense Mechanisms And The Expression Of Crinkler, NecrosisInducing Phytophthora Protein 1, And Cellulose-Binding Elicitor Lectin Pathogenic Effectors. Frontiers in Plant Science 11:16.

LeBlanc, M., G. Kim, B. Patel, V. Stromberg, and J. Westwood. 2013. Quantification Of Tomato And Arabidopsis Mobile Rnas Trafficking Into The Parasitic Plant Cuscuta pentagona. New Phytology 200:1225-1233.

Lee, K. B. 1992. On The Structure Of The Haustoria Of Some Parasitic Flowering Plants. Korean Journal of Botany 35:173-182.

Lefevere, H., L. Bauters, and G. Gheysen. 2020. Salicylic Acid Biosynthesis in Plants. Frontiers in Plant Science 11:338-345.

Li, X., Y. Zhang, J. D. Clarke, Y. Li, and X. Dong. 1999. Identification and Cloning of a Negative Regulator of Systemic Acquired Resistance, SNI1, through a Screen for Suppressors of npr1-1. Cell 98:329-339.

Manthe, B., M. Schulz, and H. Schnabl. 1992. Effects Of Salicylic-Acid On Growth And Stomatal Movements Of Vicia faba L. - Evidence For Salicylic-Acid Metabolization. Journal of Chemical Ecology 18:1525-1539.

Mauch-Mani, B., and J. P. Metraux. 1998. Salicylic Acid And Systemic Acquired Resistance To Pathogen Attack. Annals of Botany 82:535-540. 
McNeal, J. R., K. Arumugunathan, J. V. Kuehl, J. L. Boore, and C. W. Depamphilis. 2007a. Systematics And Plastid Genome Evolution Of The Cryptically Photosynthetic Parasitic Plant Genus Cuscuta (Convolvulaceae). BMC Biology 5:55.

McNeal, J. R., J. V. Kuehl, J. L. Boore, and C. W. de Pamphilis. 2007b. Complete Plastid Genome Sequences Suggest Strong Selection For Retention Of Photosynthetic Genes In The Parasitic Plant Genus Cuscuta. BMC Plant Biology 7:57.

Metraux, J. P. 2002. Recent Breakthroughs In The Study Of Salicylic Acid Biosynthesis. Trends Plant Science 7:332-334.

Mikona, C., and W. Jelkmann. 2010. Replication of Grapevine leafroll-associated virus-7 (GLRaV-7) by Cuscuta Species and Its Transmission to Herbaceous Plants. Plant Diseases 94:471-476.

Narayanan, S. P., S. C. Lung, P. Liao, C. Lo, and M. L. Chye. 2020. The Overexpression Of Osacbp5 Protects Transgenic Rice Against Necrotrophic, Hemibiotrophic And Biotrophic Pathogens. Scienctific Reports 10:19.

Olsen, S., and K. Krause. 2017. Activity Of Xyloglucan Endotransglucosylases/Hydrolases Suggests A Role During Host Invasion By The Parasitic Plant Cuscuta reflexa. PLoS One 12:e0176754.

Ridenour, W. M., R. M. Callaway, and L. A. Cavieres. 2014. Parasitism By Cuscuta chilensis And Gender Affect How The Nurse Cushion Laretia acaulis Increases Diversity In Andean Alpine Communities. Journal of Vegetation Science 25:1474-1483. 
Runyon, J. B., M. C. Mescher, G. W. Felton, and C. M. De Moraes. 2010. Parasitism By Cuscuta pentagona Sequentially Induces Ja And Sa Defence Pathways In Tomato. Plant, Cell, and Enviroment 33:290-303.

Schweiger, R., A. M. Heise, M. Persicke, and C. Mueller. 2014. Interactions Between The Jasmonic And Salicylic Acid Pathway Modulate The Plant Metabolome And Affect Herbivores Of Different Feeding Types. Plant, Cell, and Environment 37:1574-1585.

Shahid, S., G. Kim, N. R. Johnson, E. Wafula, F. Wang, C. Coruh, V. Bernal-Galeano, T. Phifer, C. W. dePamphilis, J. H. Westwood, and M. J. Axtell. 2018. MicroRNAs From The Parasitic Plant Cuscuta campestris Target Host Messenger RNAs. Nature 553:82-85.

Shen, H., W. H. Ye, L. Hong, H. L. Cao, and Z. M. Wang. 2005. Influence Of The Obligate Parasite Cuscuta Campestris On Growth And Biomass Allocation Of Its Host Mikania micrantha. Journal of Experimental Botany 56:1697-1697.

Sherman, T. D., A. J. Bowling, T. W. Barger, and K. C. Vaughn. 2008. The Vestigial Root of Dodder (Cuscuta pentagona) Seedlings. International Journal of Plant Sciences 169:9981012.

Shulaev, V., P. Silverman, and I. Raskin. 1997. Airborne Signalling By Methyl Salicylate In Plant Pathogen Resistance. Nature 386:738-738. 
Spoel, S. H., A. Koornneef, S. M. C. Claessens, J. P. Korzelius, J. A. Van Pelt, M. J. Mueller, A. J. Buchala, J. P. Metraux, R. Brown, K. Kazan, L. C. Van Loon, X. N. Dong, and C. M. J. Pieterse. 2003. Npr1 Modulates Cross-Talk Between Salicylate- And JasmonateDependent Defense Pathways Through A Novel Function In The Cytosol. Plant Cell 15:760-770.

Vinutha, H. P., B. Poornima, and B. M. Sagar. 2018. Detection of Outliers Using Interquartile Range Technique from Intrusion Dataset. Information and Decision Science 701:511518.

Vlot, A. C., D. A. Dempsey, and D. F. Klessig. 2009. Salicylic Acid, a Multifaceted Hormone to Combat Disease. Annu. Rev. Phytopathology 47:177-206

Wildermuth, M. C., J. Dewdney, G. Wu, and F. M. Ausubel. 2002. Isochorismate Synthase Is Required To Synthesize Salicylic Acid For Plant Defence. Nature 417:571-571.

Wu, J. S., L. Wang, and I. T. Baldwin. 2008. Methyl Jasmonate-Elicited Herbivore Resistance: Does MeJA Function As A Signal Without Being Hydrolyzed To JA? Planta 227:11611168.

Wu, L., H. Wu, L. Chen, H. Zhang, and X. Gao. 2017. Induction Of Systemic Disease Resistance In Nicotiana benthamiana By The Cyclodipeptides Cyclo (L-Pro-L-Pro) And Cyclo (DPro-D-Pro). Molecular Plant Pathology 18:67-74. 
Wu, L. M., Z. Y. Huang, X. Li, L. M. Ma, Q. Gu, H. J. Wu, J. Liu, R. Borriss, Z. Wu, and X. W. Gao. 2018. Stomatal Closure and SA-, JA/ET-Signaling Pathways Are Essential for Bacillus amyloliquefaciens FZB42 to Restrict Leaf Disease Caused by Phytophthora nicotianae in Nicotiana benthamiana. Frontiers in Microbiology 9:847-855.

Wu, Z., Q. Guo, M. Li, L. Jiang, F. Li, Q. Zan, and J. Zheng. 2013. Factors Restraining Parasitism Of The Invasive Vine Mikania micrantha By The Holoparasitic Plant Cuscuta Campestris. Biological Invasions 15:2755-2762.

Zhang, D., J. Qi, J. Yue, J. Huang, T. Sun, S. Li, J. F. Wen, C. Hettenhausen, J. Wu, L. Wang, H. Zhuang, J. Wu, and G. Sun. 2014. Root Parasitic Plant Orobanche aegyptiaca And Shoot Parasitic Plant Cuscuta australis Obtained Brassicaceae-Specific Strictosidine SynthaseLike Genes By Horizontal Gene Transfer. BMC Plant Biology 14:19.

Zhuang, H., J. Li, J. Song, C. Hettenhausen, M. C. Schuman, G. Sun, C. Zhang, J. Li, D. Song, and J. Wu. 2018. Aphid (Myzus persicae) Feeding On The Parasitic Plant Dodder (Cuscuta australis) Activates Defense Responses In Both The Parasite And Soybean Host. New Phytology 218:1586-1596.

Zhuk, A. V. 1997. Haustoria Morphogenesis And Origin In Cuscuta Species (Cuscutaceae). Botanicheskii Zhurnal 82:1-15. 


\section{APPENDIX: TABLES AND FIGURES}

Table 1 - Results of multivariate analysis of variance for the salicylic acid concentration of tomato above and below ground biomass. The response variables are the Log 10 transformation of the salicylic acid measurement from the above and below ground tomato tissue $(\mu \mathrm{g} / \mathrm{ml} / \mathrm{g})$

\begin{tabular}{lllllll} 
Effect & \multicolumn{2}{l}{ Pillai's Trace } & \multicolumn{3}{c}{ Standardized Canonical Coefficients } \\
\hline & df & Value & F & P & $\begin{array}{l}\text { Log Leaf } \\
\text { Conc. }\end{array}$ & $\begin{array}{l}\text { Log Root } \\
\text { Conc. }\end{array}$ \\
\hline C. pentagona & 2,31 & 0.063 & 1.03 & 0.3673 & 0.988 & 0.052 \\
P. nicotianae & 2,31 & 0.442 & 12.3 & 0.0001 & 0.049 & 1.31 \\
Co-infection & 2,31 & 0.047 & 0.76 & 0.4761 & 0.034 & 1.31 \\
\hline
\end{tabular}


Table 2 - Results of multivariate analysis of variance for the chlorophyll concentration of chlorophyll $\mathrm{a}$ and $\mathrm{b}$. The response variables are the $\log 10$ transformation of the chlorophyll and $\mathrm{b}$ measurement from the above ground tomato tissue $(\mu \mathrm{g} / \mathrm{ml} / \mathrm{g})$

\begin{tabular}{|c|c|c|c|c|c|c|}
\hline \multirow[t]{2}{*}{ Effect } & \multicolumn{3}{|c|}{ Pillai's Trace } & \multicolumn{3}{|c|}{$\begin{array}{l}\text { Standardized Canonical } \\
\text { Coefficients }\end{array}$} \\
\hline & $\mathrm{df}$ & Value & $\mathrm{F}$ & $\mathrm{P}$ & $\begin{array}{l}\text { Log10 } \\
\text { Chlorophyll } \\
\text { a }\end{array}$ & $\begin{array}{l}\text { Log } 10 \\
\text { Chlorophyll } \\
\mathrm{b}\end{array}$ \\
\hline C. pentagona & 2,35 & 0.0269 & 0.49 & 0.6197 & 0.683 & 0.328 \\
\hline P. nicotianae & 2,35 & 0.0302 & 0.54 & 0.585 & 1.040 & -0.055 \\
\hline Coinfection & 2,35 & 0.003 & 0.06 & 0.9454 & 0.923 & 0.07 \\
\hline
\end{tabular}


Table 3 - Results of multivariate analysis of variance for the salicylic acid concentration of tomato above and below ground biomass. The response variables are the Log10 transformation of the salicylic acid measurement from the above and below ground tomato tissue $(\mu \mathrm{g} / \mathrm{ml} / \mathrm{g})$ of primary and secondary host plants under attack by $P$. nicotianae.

Effect

\begin{tabular}{lcll}
\hline & df & F & P \\
\hline Primary Plant Blade & 1 & 0.15 & 0.7086 \\
& & & \\
Secondary Plant Blade & 1 & 0.60 & 0.4511 \\
& & & \\
Primary Plant Root & 1 & 0.88 & 0.3653 \\
Secondary Plant Root & 1 & 8.5 & $<.0001$ \\
\hline
\end{tabular}


Table 4 - Results of multivariate analysis of variance for the salicylic acid concentration of $C$. pentagona tissue bridging paired tomato hosts. The response variables are the Log 10 transformation of the salicylic acid measurement from the tissue directly attached to the hosts, and a middle section without haustoria attached to either tomato.

\begin{tabular}{llrrrr} 
Effect & \multicolumn{2}{l}{ Pillai's Trace } & & \multicolumn{2}{l}{ Standardized Canonical Coefficient } \\
\hline Section & df & Value & \multicolumn{1}{l}{ F } & \multicolumn{1}{l}{ P } & Log Conc. \\
& 2,39 & 0.39 & 12.44 & $<0.0001$ & 1.210 \\
Treatment & 2,39 & 0 & 0 & 0.9831 & 1.210 \\
& & & & & \\
Section*Treatment & 2,39 & 0.01 & 0.24 & 0.7877 & 1.210 \\
\hline
\end{tabular}




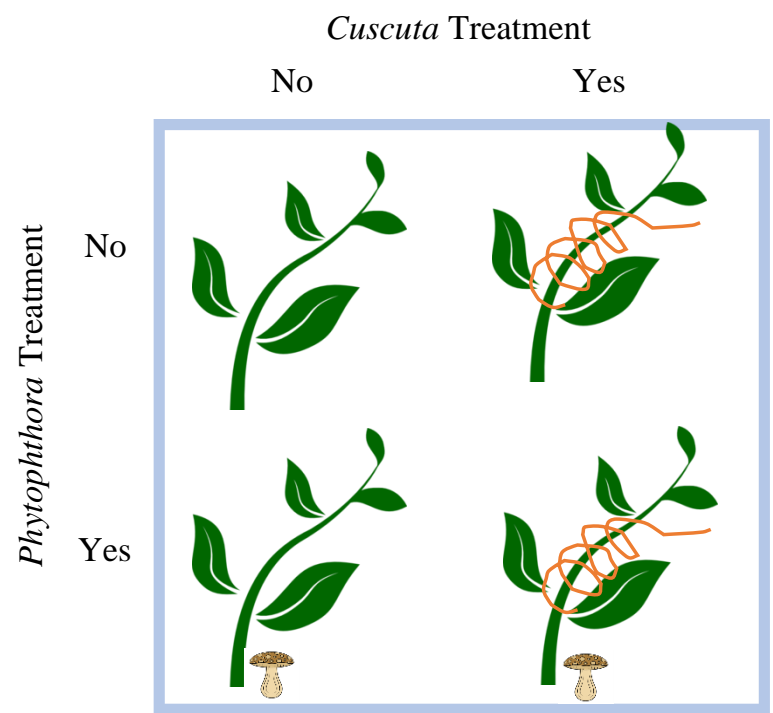

Figure 1 - Experimental design for the treatment of Solanum lycopersicum by attachment of Cuscuta pentagona preceding Phytophthora nicotianae challenge. 


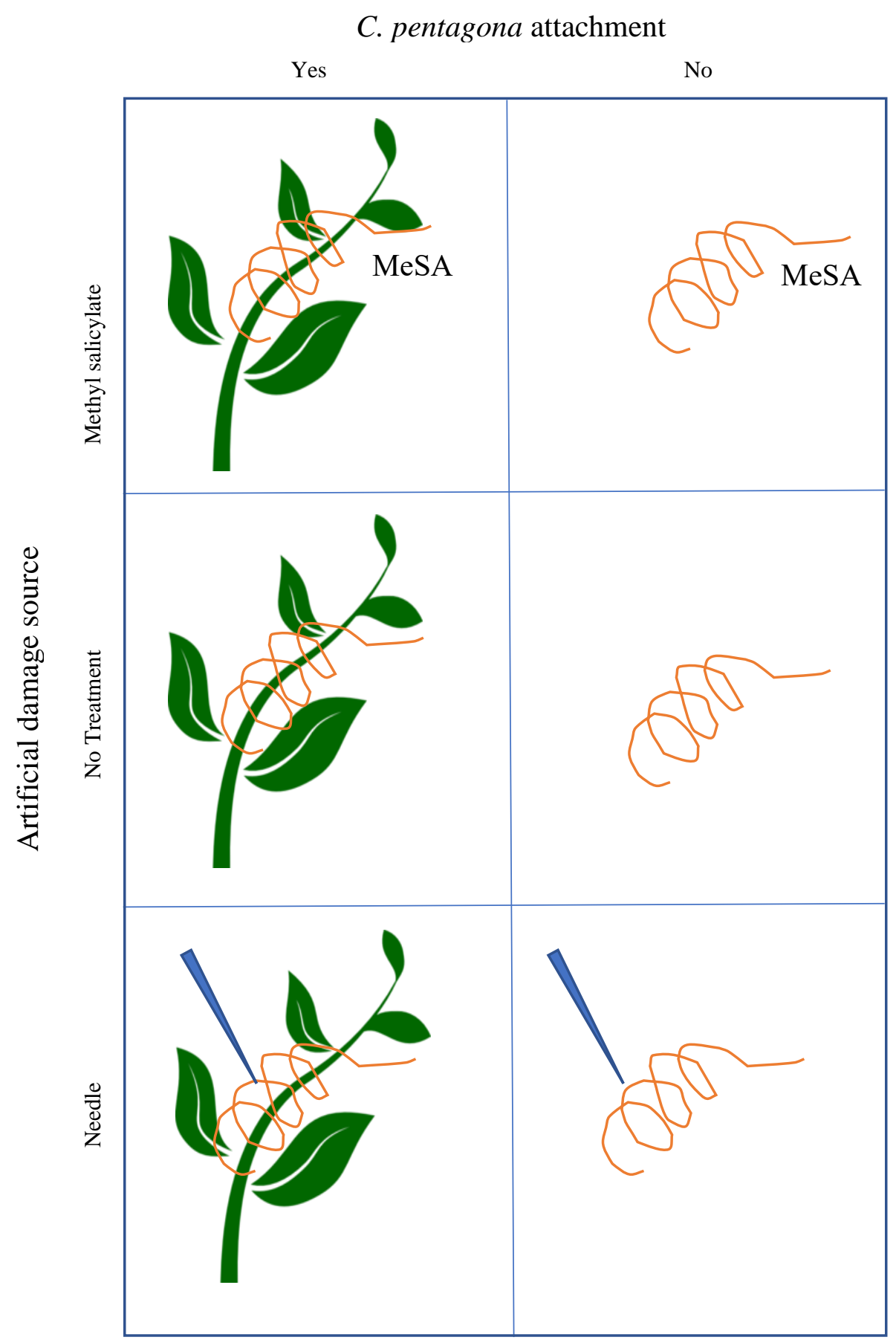

Figure 2 - Experimental design for the treatment of Cuscuta pentagon by artificial elicitors of salicylic acid before and after attachment to Solanum lycopersicum. 


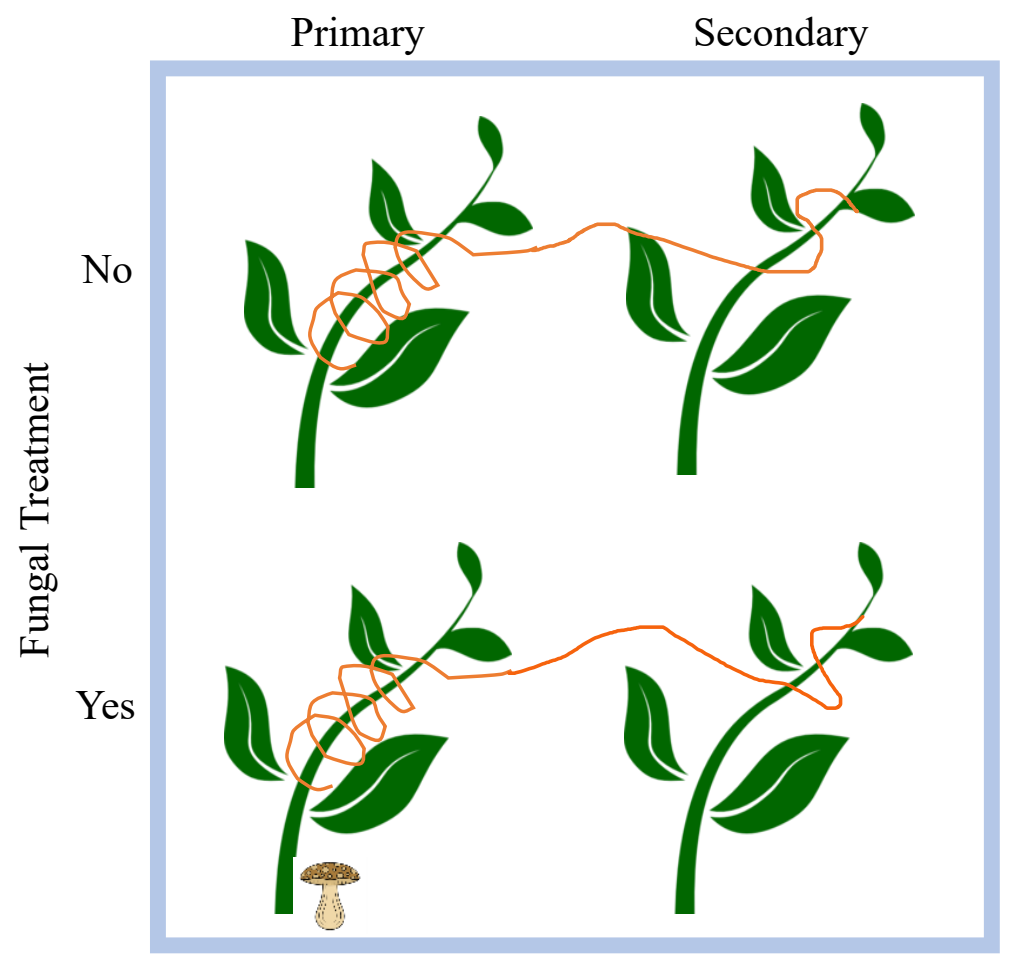

Figure 3 - Experimental design for the treatment of Solanum lycopersicum by bridging two host plants via Cuscuta pentagona when one plant in a pair is infected by $P$. nicotianae. 


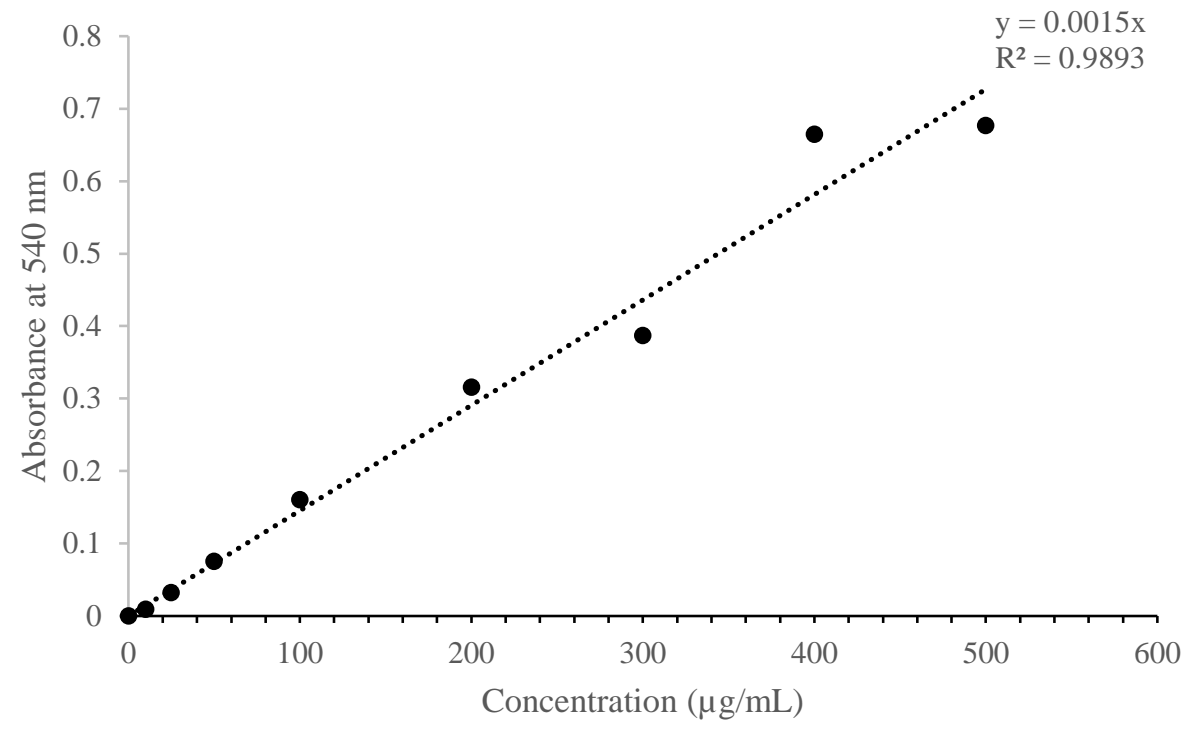

Figure 4 - Sample standard curve used for the estimation of salicylic acid in plant tissues developed from the reaction of salicylic acid and ferric chloride. 
(A)

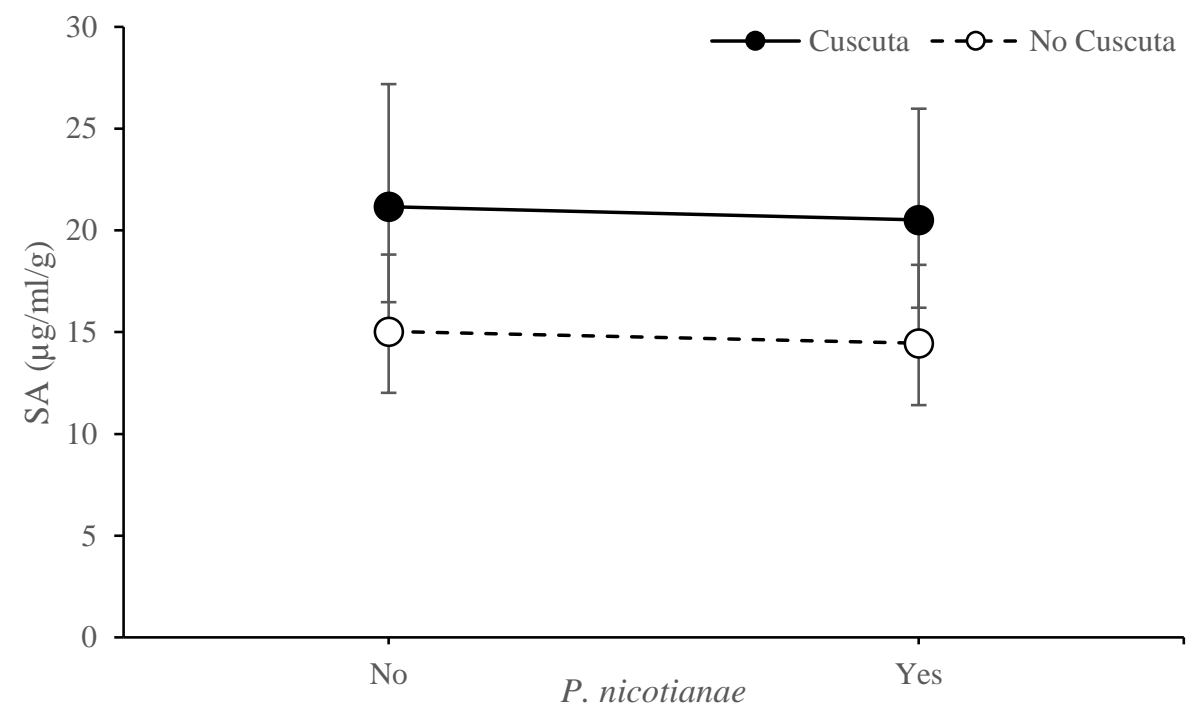

(B)

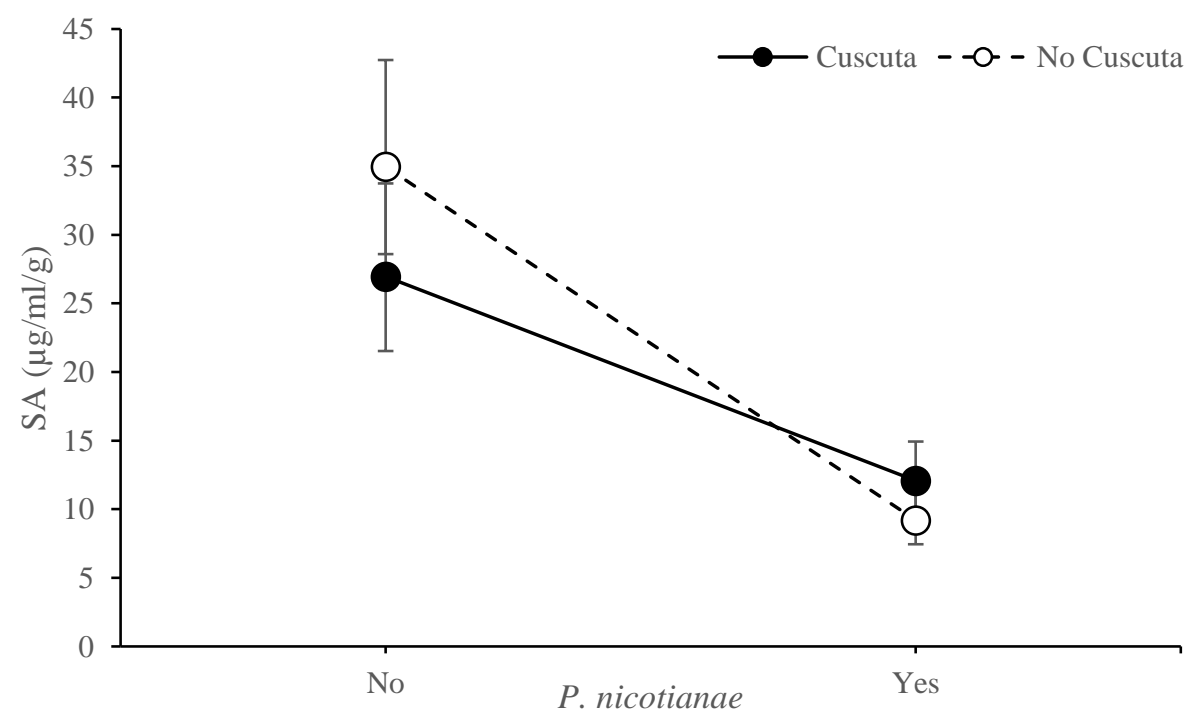

Figure 5 - Salicylic acid contents of tomato (A) blades and (B) roots, when infected by either $C$. pentagona, $P$. nicotianae, or both. Means $( \pm \mathrm{se})$ are shown. Sample size for each treatment was ten plants. 


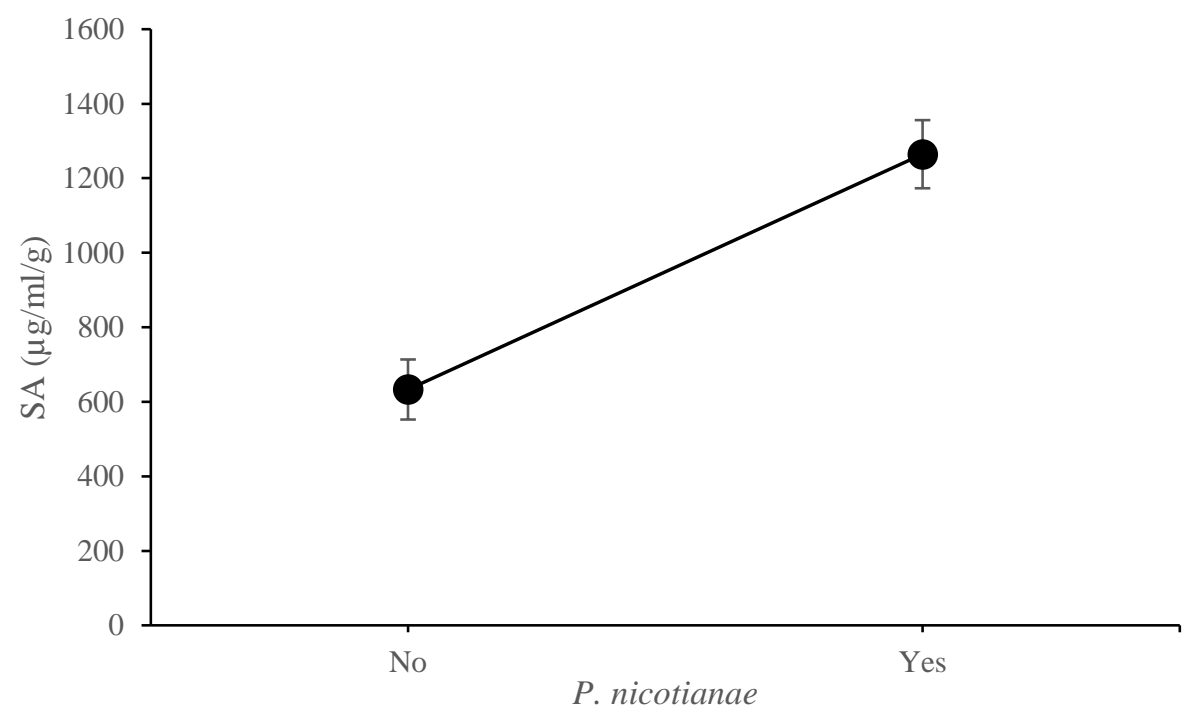

Figure 6 - Salicylic acid content of $C$. pentagona when attached to a tomato host unchallenged or infected by $P$. nicotianae. Means $( \pm$ se) are shown. Sample size for each treatment was ten plants. 
(A)

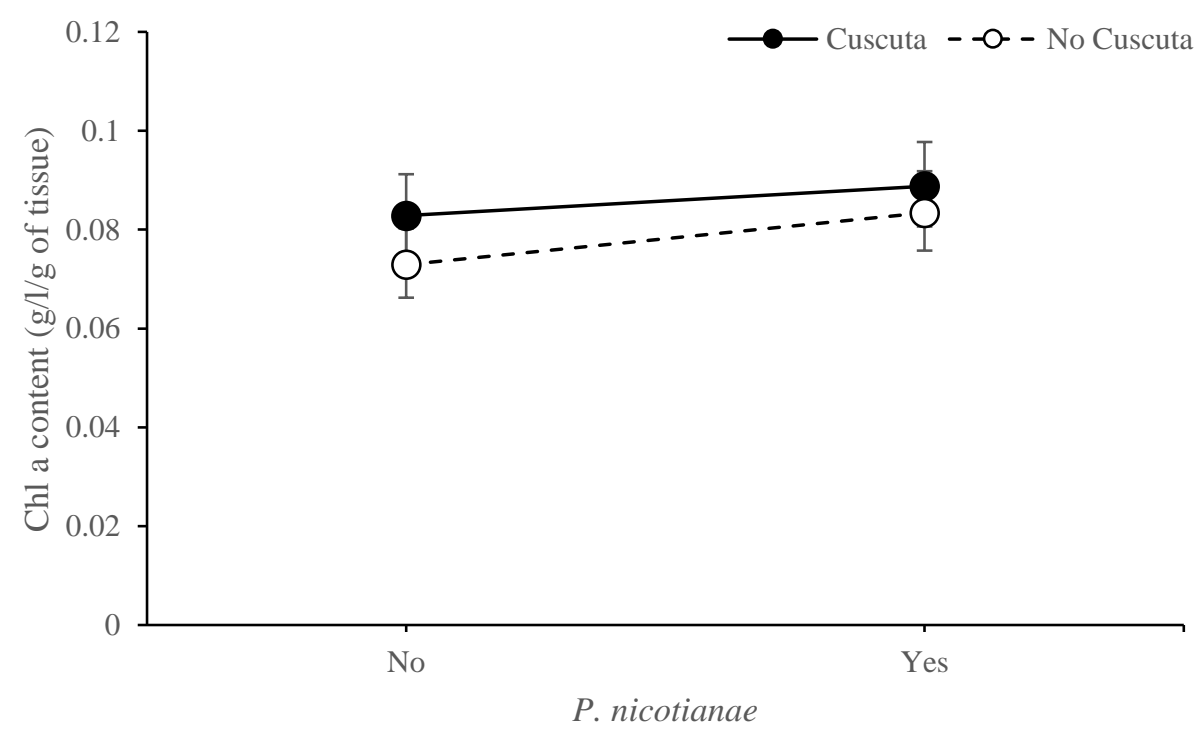

(B)

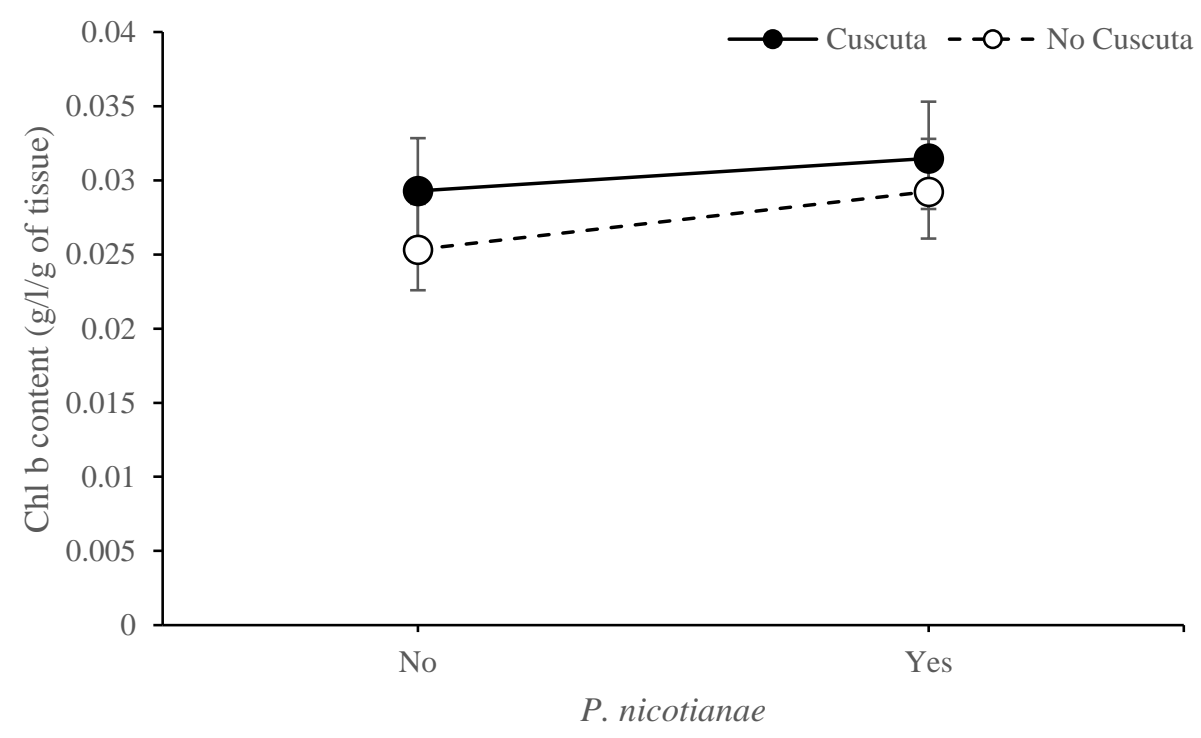

Figure 7 - Chlorophyll content of tomato leaf tissue from plants infected by either C. pentagona, $P$. nicotianae, or both for (A) chlorophyll a, and (B) chlorophyll b. Means $( \pm$ se) are shown. Sample size for each treatment was ten plants. 


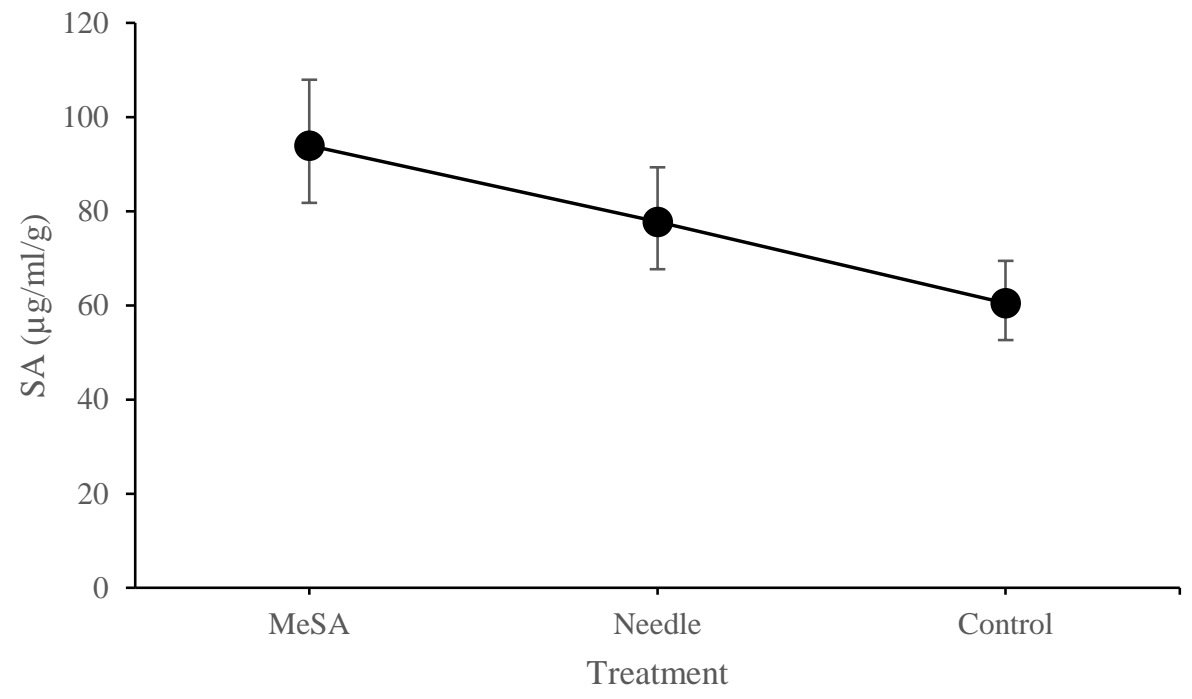

Figure 8 - Salicylic acid content of tomato leaves when parasitized by $C$. pentagona and exposed to methyl salicylate (MeSA), needle damage applied to the $C$. pentagona, or left untreated. MeSA and control are marginally significantly different $(P=0.055)$. Means $( \pm$ se $)$ are shown. Sample size for each treatment was ten plants. 


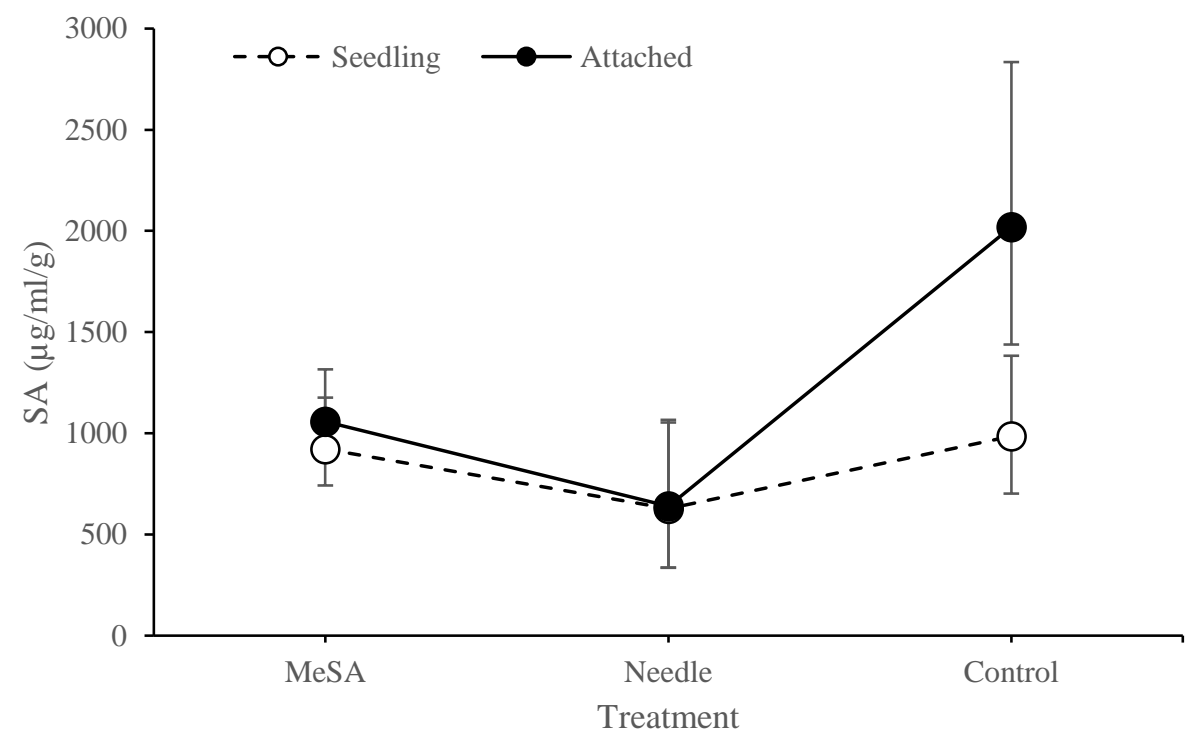

Figure 9 - Salicylic acid content of $C$. pentagona tissue attached and unattached to a tomato host, when exposed to methyl salicylate (MeSA), damaged by needle, and left untreated. Means ( \pm se) are shown. Sample size for each treatment was ten plants. 
(A)

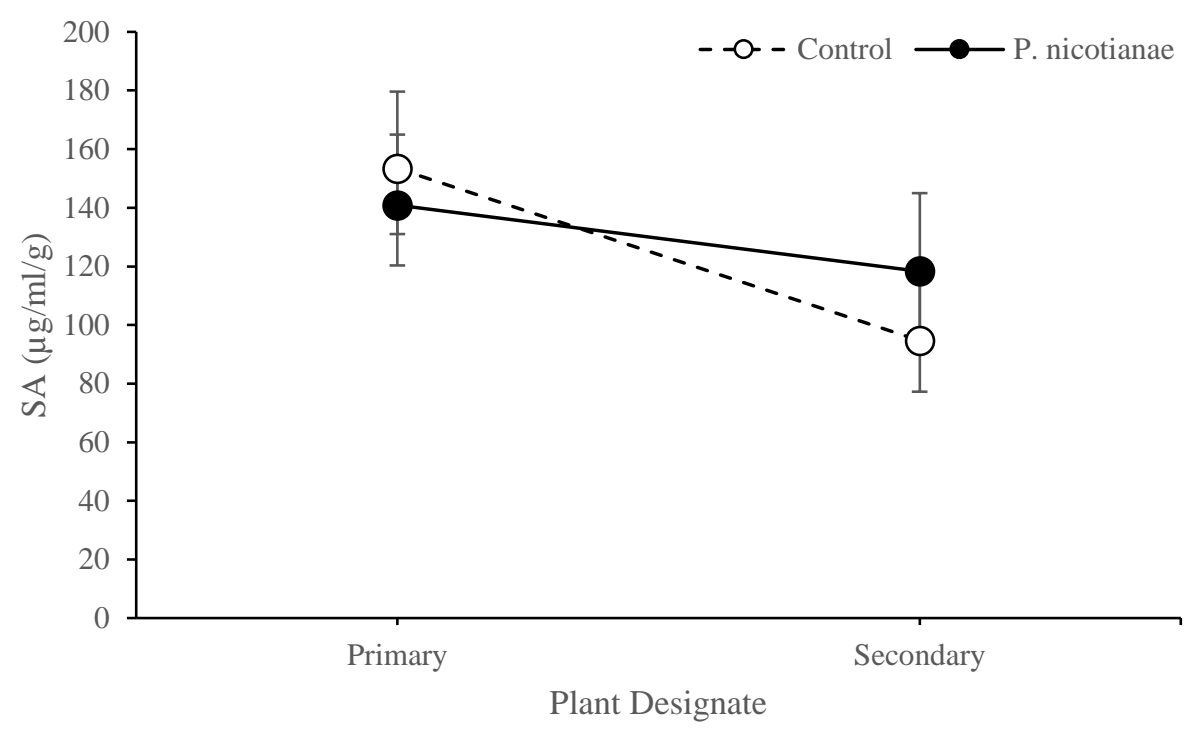

(B)

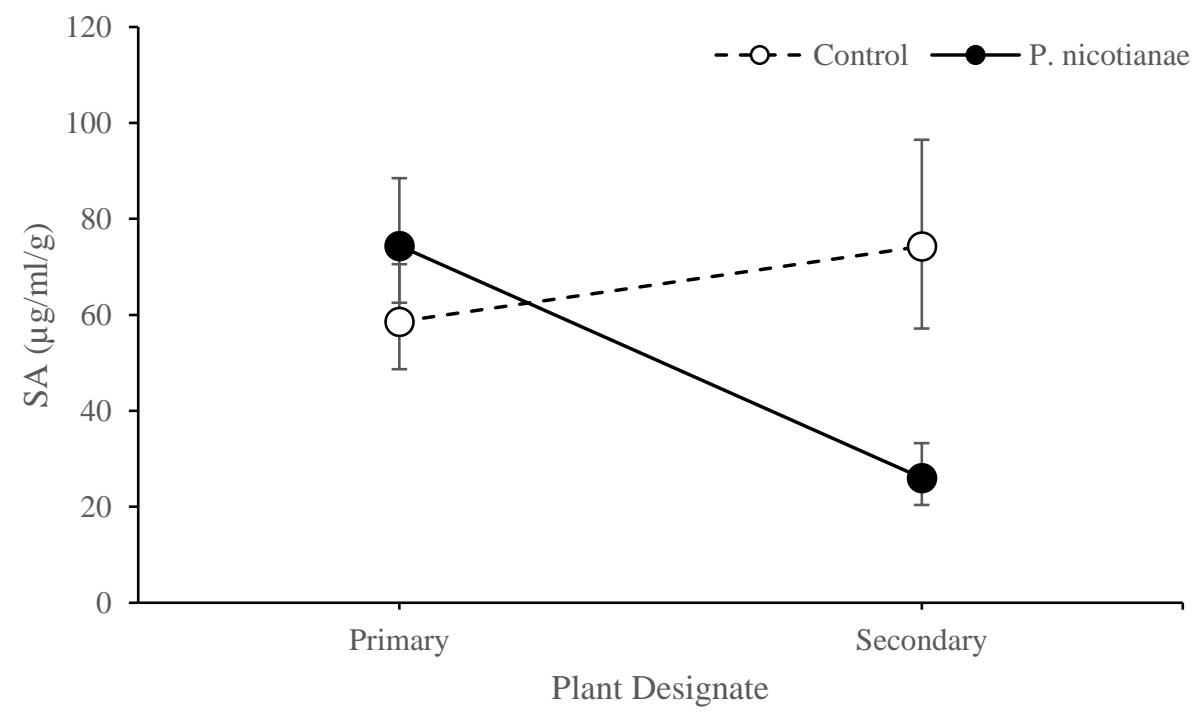

Figure 10 - Salicylic acid content of (A) blades and (B) roots of tomato plants paired by $C$. pentagona bridging when infected and uninfected by $P$. nicotianae. The $1^{\circ}$ designate describes the plant to which $C$. pentagona attached first and, if applicable, was directly exposed to $P$. nicotianae. The $2^{\circ}$ designate describe the plant to which $C$. pentagona attached second and was not directly exposed to $P$. nicotianae. Means $( \pm s e)$ are shown. Sample size for each treatment was eight plants. 


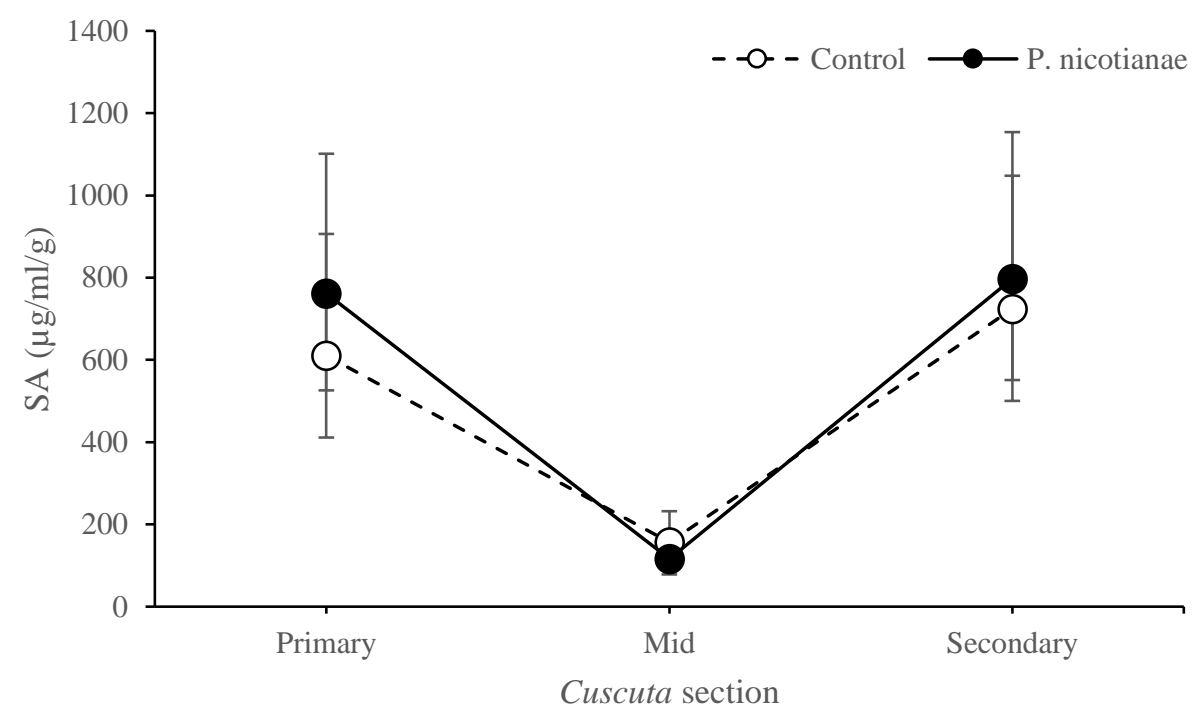

Figure 11 - Salicylic acid content of $C$. pentagona tissue attached to tomato pairs, either infected or uninfected by $P$. nicotianae. Tissue samples were taken from the attachment point nearest to the blade harvested for salicylic acid measurement, and from an approximate mid section of the vine bridging the two plants. Means $( \pm$ se) are shown. Sample size for each treatment was eight plants. 
(A)

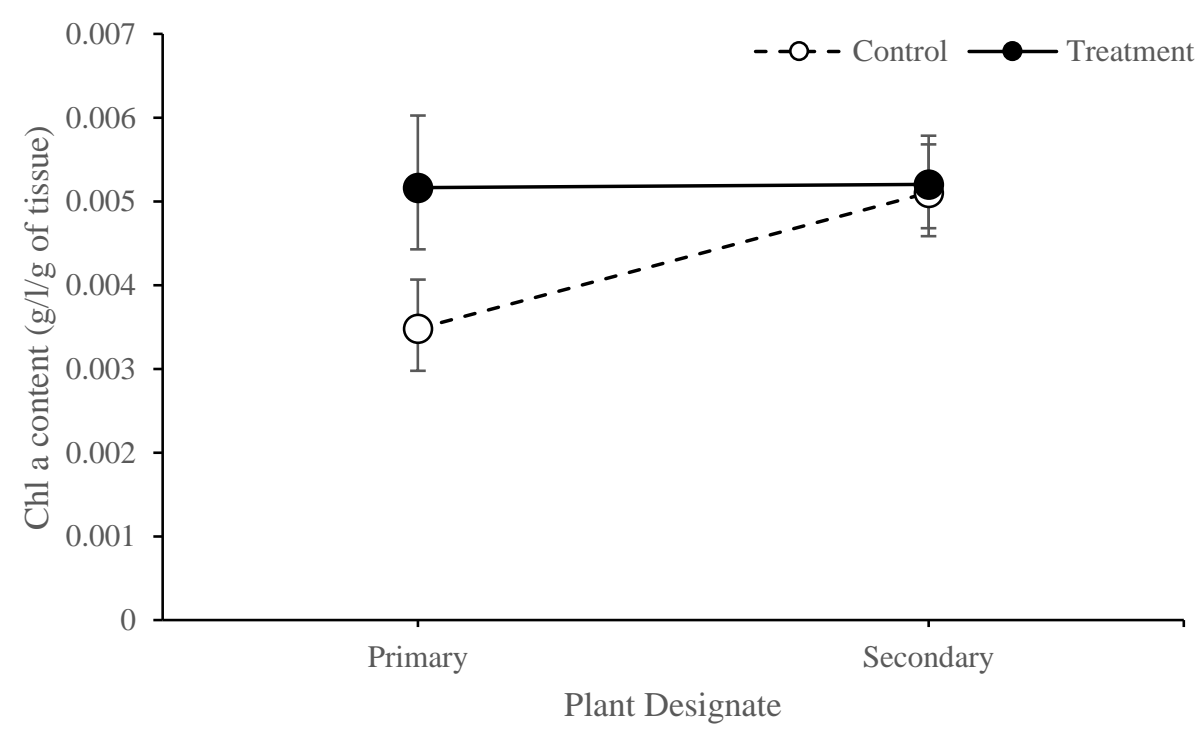

(B)

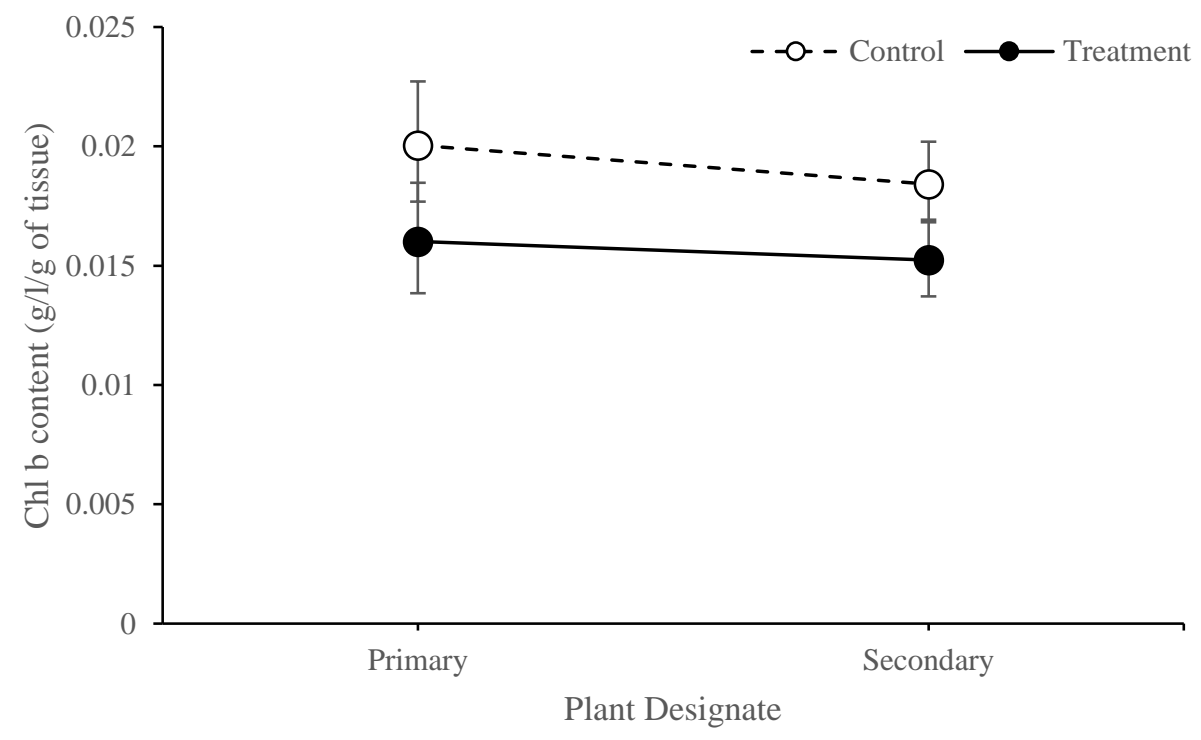

Figure 12 - (A) Chlorophyll a and (B) chlorophyll b content of tomato leaf tissue from plants paired by $C$. pentagona bridging when infected and uninfected by $P$. nicotianae. The $1^{\circ}$ designate describes the plant to which $C$. pentagona attached first and, if applicable, was directly exposed to $P$. nicotianae. The $2^{\circ}$ designate describe the plant to which $C$. pentagona attached second and was not directly exposed to $P$. nicotianae. Means $( \pm \mathrm{se})$ are shown. Sample size for each treatment was eight plants. 